\title{
Abdominal pain models: mechanisms and therapies and experimental models
}

\author{
E. Lucarini, L. Di Cesare Mannelli, C. Ghelardini \\ Department of Neuroscience, Psychology, Pharmacology and Child Health (NEUROFARBA), University of \\ Florence
}

E-mail: elena.lucarini@unifi.it

\section{Summary}

Chronic or recurrent abdominal pain is the most prevalent gastrointestinal disorder, affecting $10 \%$ of the general population, including children and adolescents. It is a common feature of both intestinal functional disorders, like irritable bowel syndrome (IBS), and inflammatory bowel diseases (IBDs). These two conditions often overlap from the clinical point of view since a large subset of IBD patients experience persistent abdominal pain even after reaching remission from the intestinal inflammation, developing a condition called IBS-like. Visceral pain management is a major clinical problem in these patients since the lack of effective and safe drugs. Despite the large number of sufferers, the mechanisms that drive the development and the persistence of chronic abdominal pain remain largely unresolved and this presents a major barrier to progress in the development of new therapies. Chronic abdominal pain often displays a complex nature with mixed nociceptive, inflammatory, emotional and neuropathic components. This is mainly attributable to the intricated regulation of visceral sensitivity which involves many actors in the gut as well as in the peripheral and central nervous systems. In this text we describe the neuroanatomical bases of visceral pain signalling, the pathophysiological mechanisms involved in pain persistence and how current treatments work, including an overview of potential new targets. In the context of drug discovery, the potential advantages and disadvantages of different preclinical models of visceral pain were also discussed. 


\section{Graphical summary}

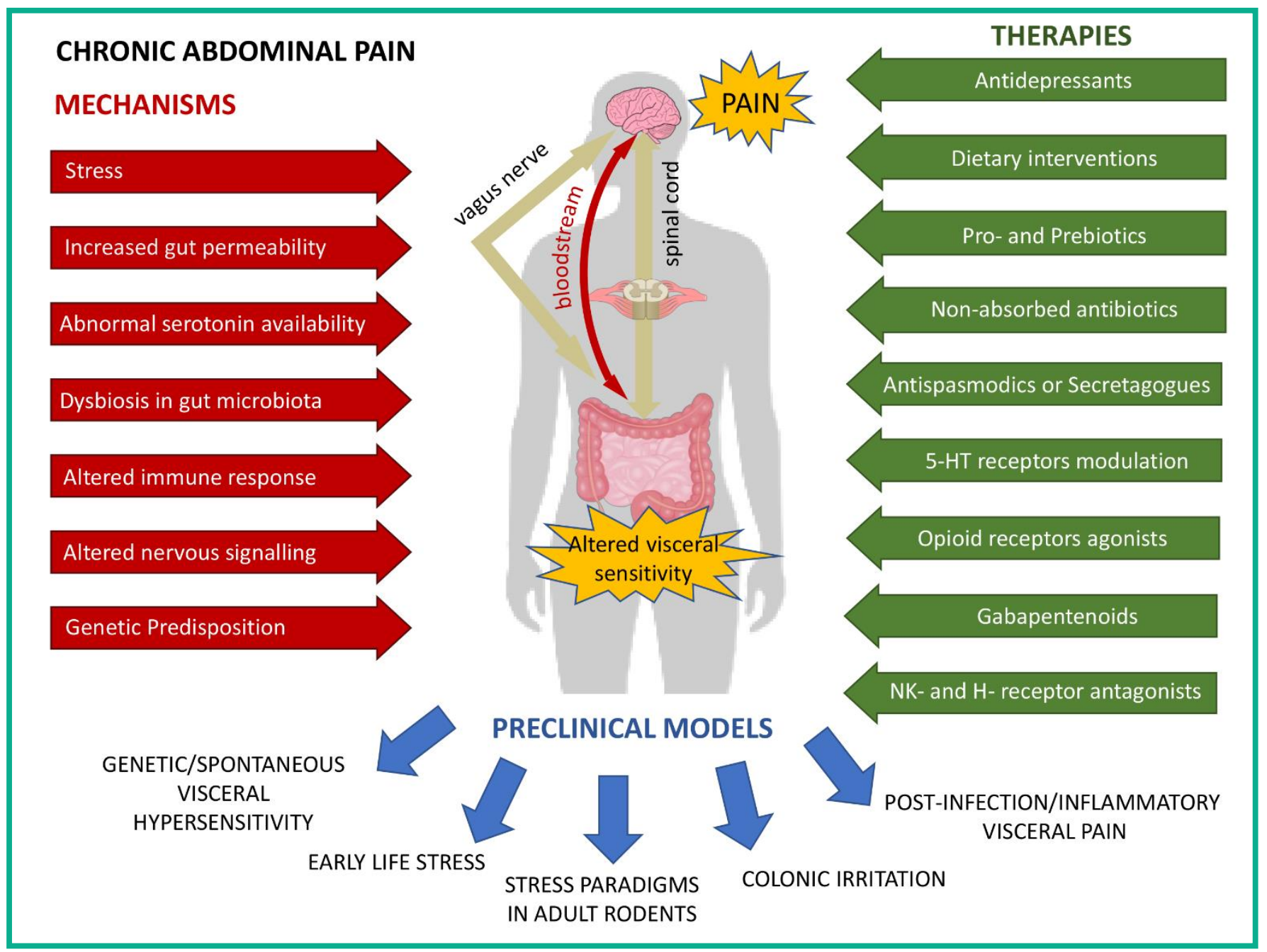

\section{Visceral pain}

Visceral pain is by definition pain sensed as arising from the internal organs of the body. It results from the activation of nociceptors of the thoracic, pelvic, or abdominal viscera.

There are multiple etiologies for visceral pain, including: inflammation (acute and chronic), mechanical irritants (e.g., kidney stones), infection, disruption of normal mechanical processes (e.g., gastrointestinal dysmotility), neoplasms (benign or malignant), alterations in nerves carrying sensations from the viscera, ischemia (1). Visceral structures are highly sensitive to distension (stretch), ischemia and inflammation, but relatively insensitive to other stimuli that normally evoke pain such as cutting or burning (2).

Although there are many commonalities in the processing of somatic and visceral pain, there are also several important clinical distinctions. Firstly, pain cannot be evoked from all viscera.

Besides injury to the viscera does not necessarily cause pain. Visceral pain is perceived more diffusely than noxious cutaneous stimulation with respect to location and timing, owing to relatively few visceral afferents with extensive receptive fields $(1,3)$.

Pain from different visceral organs can have differing areas of presentation, e.g. bladder to perineal area, heart to left arm and neck, left ureter to left 
lower quadrant and loin. This diffuse nature and difficulty in locating visceral pain is due to a low density of visceral sensory innervation and extensive divergence of visceral input within the Central Nervous System (CNS). Spatial discrimination of visceral pain is thus typically referred to superficial structures to produce secondary hyperalgesia of superficial or deep body wall tissues due to viscerasomatic convergence into shared spinal levels $(4,5)$. This "referred pain" is better localized and therefore difficult to differentiate from pain of somatic origin. Furthermore, visceral pain is often associated with marked autonomic phenomena, including pallor, profuse sweating, nausea, muscle tension, gastrointestinal (GI) disturbances and changes in body temperature, blood pressure and heart rate $(1,3)$.

\section{Chronic visceral pain}

It has been estimated that $\sim 40 \%$ of population experience a chronic or persistent pain from internal organs. Traditionally, chronic visceral pain has been categorized as either "organic," caused by a pathological lesion that is detectable by standard diagnostic measures, or "functional," where the etiology remains obscure and may be due to yet undefined changes in visceral sensitivity at either the peripheral or central level (1). Abdominal pain is the most common visceral pain and results in more than 15 million office visits per year. Chronic abdominal pain affects at least $10 \%-15 \%$ of the general population and is a characteristic feature of functional bowel disorders, such as irritable bowel syndrome (IBS), the inflammatory bowel diseases (IBDs), and is a growing problem associated with chronic opioid use (6-8).

\section{Visceral pain in IBS}

IBS is the most commonly diagnosed chronic gastrointestinal disease, prevalence rates of IBS vary between $1.1 \%$ and $45 \%$, based on population studies from countries worldwide $(6,9)$. According to the Rome III criteria, IBS is defined based on the presence of chronic/recurrent abdominal pain or discomfort at least three days per month in the past three months associated with two or more of the following: 1) improvement with defecation; 2) onset associated with a change in frequency of stool; and 3 ) onset associated with a change in form (appearance) of stool (6).

Rome III criteria subtype IBS according to the predominant bowel habit as IBS with constipation (IBS-C), IBS with diarrhea (IBS-D), mixed type, and unclassified (6). To this end, the definition of bowel-habit type is based on the patient's description of the stool form by referring to the Bristol Stool Scale (10).

Nevertheless, IBS symptoms cannot be explained by structural abnormalities, and specific laboratory tests or biomarkers are not available for IBS. Therefore, IBS is classified as a "functional" disorder whose diagnosis depends on the history of manifested symptoms (11). IBS patients can be further divided into two categories: sporadic (nonspecific) and postinfectious or inflammatory bowel diseaseassociated (PI-IBS). Meta-analyses suggest that gastroenteritis increases the risk of developing IBS sixfold, making it one of the strongest risk factors for IBS. PI-IBS shows clearly that acute inflammation followed by mucosal healing can cause the development of chronic IBS symptoms (12-14). Early studies suggested adverse psychological features were less common in PI-IBS, but other studies suggest that hypochondriasis, anxiety, depression and somatization are important risk factors for developing PI-IBS, as they are for all IBS subtypes (14-17). Regarding the pathophysiological mechanisms of IBS, though routine histologic examinations do not show significant colonic mucosal abnormalities in the majority of IBS patients, however, recent quantitative histologic, immunohistochemical, and ultrastructural analyses have indicated subtle organic alterations in these patients, like an increase in histamine levels in the gut (18).

\section{Visceral pain in IBDs}

IBDs which are comprised of two main types, ulcerative colitis (UC) and Crohn's disease (CD), affects approximately 3.6 million people in the United 
States and Europe (6). Although considerable progress has been made in recent years, a major gap in knowledge of the pathogenesis of chronic visceral hypersensitivity in IBD patient remains and consequently effective treatments are still lacking. IBD is characterized by chronic or relapsing immune activation and inflammation within the gastrointestinal (GI) tract that markedly alters GI function (19). When the gut is inflamed, there is breakdown of intestinal barrier function, abnormal secretion, changes in the patterns of motility and visceral sensation, which contributes to symptom generation (diarrhoea, cramping, and pain) (20).

Although abdominal pain has been traditionally associated with inflammatory flare-ups in IBD, a large subset of patients that suffer from IBD eventually develop chronic abdominal pain even after achieving clinical remission. This condition, called comorbid IBS (loosely termed "IBS-IBD"), is present in up to $46 \%-59 \%$ of patients with Crohn's disease and $36 \%-38 \%$ of patients with ulcerative colitis in remission (21-23).

Abdominal pain linked to these disorders is common in adults and pediatric patients and is a major contributing factor to their low quality of life and high morbidity. As a result, the Food and Drug Administration (FDA) now requires the use of abdominal pain as a patient-reported outcome to assess the efficacy of new therapies for Crohn's disease (8).

The mechanisms that drive the development of chronic abdominal pain remain largely unresolved and this presents a major barrier to progress in the development of new therapies. Current therapies for IBD primarily focus on controlling inflammation with amino salicylates, corticosteroids, immunomodulators, and biologic agents. Although these agents clearly benefit the treatment of active inflammation, they do not address abdominal pain (24).

Opioids are the current frontline therapy for chronic abdominal pain, but chronic opioid use has serious complications and produces a condition called narcotic bowel syndrome that is characterized by ab- dominal pain (25). This is a serious and growing issue that requires a more sophisticated understanding of the causal mechanisms to permit the development of more effective therapies.

\section{Visceral pain comorbidities}

Visceral pain is reported to be frequently associated with both somatic and psychiatric disorders. Among the somatic comorbidities, the association between IBS and fibromyalgia is the most studied, with the IBS-symptoms occurrence in an estimated $48 \%$ (range, 32\%-77\%) of patients with fibromyalgia. All of these incidence rates are significantly higher than those in other gastrointestinal patients (26). Anxiety and depression are the most commonly reported psychiatric comorbidities in chronic visceral pain syndromes (27-30). Several clinical studies have suggested that psychosocial comorbidity is a major contributor to the severity and impact on quality of life of visceral pain disorders such as IBS and somatic pain disorders such as fibromyalgia (31-33). These findings are reinforced by a considerable volume of experimental research that links stress, anxiety, and depression to altered GI sensory and motor function as well as altered pain processing (34). This implies that a successful management of patients with visceral pain disorders requires careful attention to these psychosocial factors, often in consultation with mental health professionals (35). Antidepressants are often used to treat the anxiety and depression that is commonly experienced by patients with IBD and IBS, wherein they have also been shown to be effective in treating associated gastrointestinal symptoms (36).

\section{Visceral pain assessment in patients}

«...But when you cannot measure it, when you cannot express it in numbers, your knowledge is of a meagre and unsatisfactory kind» (Lord Kelvin Lecture, Electrical Units of Measurement,1893). Pain intensity is influenced by the meaning of the pain to the patient and by his emotional state, such as fear, 
anxiety and depression (37). Indeed, in many cases, like GI diseases, pathology does not correlate well with pain (37-39). For these reasons, valid and reliable assessment of pain is essential for both clinical trials and effective pain management.

A multitude of different instruments is currently used to assess chronic abdominal pain in patients, making it difficult to compare endpoints of published studies. Among the questionnaires available, the validated IBS-Symptom Severity Scale includes the broadest measurement of pain-related aspects (40). Traditionally, visceral perception has been tested by delivering a certain controlled sensory stimulus and measuring the nociceptive response evoked by it. The GI tract contains afferents that encode a wide range of intensities and modalities of stimulation including electrical, mechanical, thermal and chemical (including nutrient) stimuli (41). Choosing the correct stimulation method or interpreting differential responses to multiple stimuli may be of superior relevance in delineating pathological mechanisms (42). Measurement of the pain response using verbal scores and scales to assess perceptive intensity and thresholds of nociception is largely influenced by subjective components, making it prone to reporting bias. Visual analog scales have emerged as having psychometric properties that are superior to the other pain scaling methods because they fulfil multiple criteria for ideal pain measurement and assessment (43). On the other hand, with brain imaging and neurophysiological measurements, theoretically offering a more objective assessment of nociceptive responses, the outcome measures are also greatly affected by cognitive-affective mechanisms, posing a challenge to the search for a surrogate marker of altered visceral perception in patients (41). The most commonly used brain imaging entity, functional magnetic resonance imaging (fMRI), is based on the difference in the magnetic properties of oxygenated and deoxygenated blood, specifically the difference in decay time of the magnetic resonance signal from oxyhemoglobin and deoxyhemoglobin, referred to as the blood oxygenation level-dependent technique. This difference in signal characteristics allows for the localized detection of regional cerebral blood flow (rCBF). fMRI has an excellent spatial resolution (2$5 \mathrm{~mm}$ ), especially in the more superficial layers. Limitations are seen in the deeper structures, such as the brain stem and thalamus, owing to pulsation artifacts. The temporal resolution is poor (1-3 s), and therefore fMRI is not a specific tool for investigating the neuronal activity directly related to the painful stimuli. Since the exogenous brain activity takes place within the first $150 \mathrm{~ms}$ poststimulus, the response may miss the fast-occurring activity and model, instead, the endogenous activity rather than brain responses due to pain. Anyway, comparison of images recorded during resting and active periods following administration of a nociceptive stimulus, for instance rectal distension, reveals regions of increased cortical activity, and these measures have been used to increase understanding of the functional properties of the brain (41).

\section{Perceptional response to mechanical stimuli (rectal distension)}

Until recently, employing gut distensions has most widely been used to test visceral perception in IBS. It has been reported that 35-60\% IBS patients exhibit increased visceral sensitivity to rectal balloon distension (44-47).

Both rectal and sigmoid distensions have been employed, although the overwhelming majority of studies have applied rectal distensions. In fact, the more accessibility and the grater content of sensitive afferents make the rectum an ideal target in assessing visceral nociception (48).

Rectal visceral sensitivity can be tested by using polyethylene bags in conjunction with a barostat used to maintain the intra-rectal pressure and volume (49). Several different distention protocols have been applied to assess visceral perception in IBS $(41,50)$.

Distension paradigms differ in duration and type of inflation (tonic vs. phasic), level of bias (ascending vs. randomized distension), and measurement of response magnitude (perceptual threshold or rating). 
During rectal distension, several parameters of visceral sensitivity can be collected to assess perceptional status.

These include perceived intensity of the stimulus, extent of the viscerosomatic referral area and the threshold at which different sensations (pain, discomfort, urge) appear during the distension protocol (51). These components of visceral perception are not uniformly used by various groups, making comparison of study results troublesome (41). The majority of the research groups investigating visceral perception using the barostat techniques have focused on identifying the thresholds for perception in IBS patients because these have been shown to be lowered compared with healthy volunteers. However, threshold measurements of pain perception are limited since they fail to assess alterations in pain intensity that may occur over a wide range of noxious intensities. On the other hand, investigation of the perceived intensity of the given stimulus as well as recording the viscerosomatic referral area can give extra information on processing of visceral stimuli $(51,52)$. In addition to lowered thresholds to visceral stimuli, marked alterations in somatic referral patterns in response to balloon distension of the colon have been described in patients with IBS. This is a strong indication for altered spinal processing of visceral sensory information and is a manifestation of central sensitization (41). Despite the fact that not all patients exhibit hypersensitivity to rectal distensions, the barostat procedure appears to be a reliable and valid approach to assess visceral nociception (50). However, bowel symptoms in IBS patients often exacerbate after food consumption. There is ample evidence that GI nutrient content may either be the source of or contribute to abnormal, painful, or uncomfortable visceral perception in IBS. Therefore, testing of visceral sensitivity in IBS patients in a postprandial state can also have an added value in assessing visceral perceptional status (41).

Perceptional response to non-mechanical stimuli Besides mechanical stimulation, a number of other stimulation modalities have been used to assess visceral sensitivity. Transmucosal electric nerve stimulation, for instance, induces perception by nonspecific stimulation of afferent pathways without the involvement of a specific receptive unit. However, whereas IBS patients had lower sensory thresholds to mechanical stimulation of the small intestine compared with controls, thresholds to electrical intestinal stimulation were similar in IBS patients and controls. A disadvantage of using electrical stimulation is the nonspecific activation of nerve endings, resulting in neural discharge from nerves, which might not otherwise be activated during nociceptive processes $(53,54)$.

Similarly, to mechanical stimuli, IBS patients also demonstrate lower thresholds to thermal stimulation of the rectum $(53,54)$.

Capsaicin is the most commonly used chemical stimulus in the studies on somatic pain and has also been successfully used to evaluate chemical hypersensitivity in functional dyspepsia $(55,56)$. Intestinal capsaicin infusion results in a sensation of warmth and burning, in addition to the generation of cramps, acting directly on mechanosensitive afferents. Moreover, the time to first sensation of a second capsaicin infusion is significantly reduced, suggesting the induction of peripheral sensitization of capsaicin-sensitive afferents (55).

Anyway, drawbacks of chemical stimuli include relative long latency time to onset of effects, compared with other stimulation modalities, and the fact that these effects are often not reproducible (57). Therefore, validation of results using chemical stimulation in IBS is still warranted.

\section{Visceral pain pathways}

The perception of pain involves the integration of neurobiological pathways within the enteric, peripheral, and central nervous systems (19). The gastrointestinal tract differs from all other peripheral organs. An extensive intrinsic nervous system, termed enteric nervous system (ENS) controls digestive and defensive functions of the intestine even 
when it is completely separated from the central nervous system (CNS).

The ENS, however, is not autonomous. Indeed, neuronal control of gastrointestinal function is an integrated system involving interactions between local enteric reflexes, reflexes that pass through sympathetic ganglia and reflexes that pass from the gut and back through the CNS (58).

\section{Enteric nervous system}

The ENS regulates and coordinates almost all aspects of intestinal function including gut motility, transport of fluid and electrolytes, secretion of mucins, production of cytokines, and the regulation of epithelial barrier function (58). Each of these aspects of physiology are compromised in IBDs and IBS patients, whereby it is not surprising that there is an increasing amount of research interest in elucidating the role of the ENS in the pathogenesis of these GI disorders (59). Enteric ganglia are organized into two major ganglionated plexuses, the myenteric (Auerbach's) and submucosal (Meissner's) plexus. They contain a variety of functionally distinct neurons, including primary afferent neurons, interneurons, and motor neurons, synaptically linked to each other in microcircuits (58). The rich sensory innervation of the gastrointestinal tract comprises intrinsic sensory neurones contained entirely within the gastrointestinal wall, intestine-fugal fibres that project to prevertebral ganglia, and vagal and spinal afferents that project into the CNS (60). The morphological appearance of afferent terminals in the gastrointestinal wall, visualised by fluorescent microscopy, suggests that these endings may also subserve an "efferent" sensorimotor function. Gastrointestinal afferents are thought to have collateral branches that supply blood vessels and innervate the enteric ganglia where they have the potential to modulate blood flow and enteric reflex pathways as a consequence of release of transmitters from their varicose nerve terminals (61).

Besides, viscerofugal neurons have cell bodies within the myenteric plexus, but have projections out of the gut wall, via extrinsic nerve trucks, to prevertebral ganglia. These viscerofugal neurons sense and receive information regarding mechanical distension of the intestine and transmit this information to postganglionic sympathetic visceromotor neurons in the prevertebral ganglia (58). In addition to the enteric nervous system, gut epithelium is another site for detecting dietary, microbial, and inflammatory stimulus. Among the epithelial cells, serotonergic entero-chromaffin (EC) cells are proposed to fulfil this role by acting as chemosensors. Studies conducted on cultured intestinal organoids showed that EC cells express specific chemosensory receptors, are electrically excitable, and modulate serotonin-sensitive primary afferent nerve fibers via synaptic connections, enabling them to detect and transduce environmental, metabolic, and homeostatic information from the gut directly to the nervous system (62).

\section{Peripheral visceral neurotransmission}

Visceral sensory afferents are almost exclusively thinly myelinated $\mathrm{A} \delta$-fibres and unmyelinated $\mathrm{C}$-fibres. However, the distinction between nociceptive afferents and non-nociceptive afferents is not clear in visceral neurotransmission compared to somatic nociception, given the functional division of mechano-sensitive visceral receptors into two physiological classes (63). "High-threshold receptors" in organs such as the heart, oesophagus, colon, ureter and uterus respond only to noxious mechanical stimuli. 'Low-threshold receptors' are intensity-encoding and thus respond to a range of innocuous to noxious stimuli.

An important contrast with somatic nociception is the role of low-threshold A $\beta$-fibres, which only convey innocuous mechanical sensations in normal conditions (5).

Viscera are also innervated by so-called 'silent' nociceptors, more accurately designated as mechanically insensitive afferents (MIAs).

These can acquire mechanosensitivity following inflammation and have been thoroughly characterised 
in significant proportions in rodent pelvic and splanchnic innervations of colorectum and in human microneurographic studies of cutaneous C-afferents (64).

Recently, a research group of Pittsburgh demonstrated that extrinsic primary afferent neurons (ExPANs) link visceral pain to colon motility through a spinal reflex in mice. Indeed, proper colon function requires signals from ExPANs located in spinal ganglia. Besides, ExPAN stimulation initiates myenteric neuron activity and subsequent colon contractions, but only in the presence of an intact spinal cord, confirming the presence of a sensoryparasympathetic spinal circuit regulating colonic motility. The described circuit demonstrated how visceral pain is linked to colon motility and explain why pain and dysmotility co-occur in GI disorders (65). Anyway, these results complicate further the network at the base of visceral sensitivity and might preclude the possibility of achieving a selective modulation of pain.

Visceral fibres can serve "sensory" and "afferent" functions: the former can evoke conscious sensations and the latter regulate autonomic flow. Afferent fibres innervating viscera project to the CNS through autonomic sympathetic and parasympathetic nerves, a dual sensory innervation (66). The cell bodies of vagal and spinal visceral afferents are contained within the nodose and dorsal root ganglia. Some spinal afferents travel along hypogastric, lumbar colonic and splanchnic nerves to terminate in thoracolumbar regions as part of sympathetic innervation, traversing both prevertebral and paravertebral ganglia on route to the spinal cord Vagal and pelvic afferents respectively terminate in the brainstem and lumbosacral cord and contribute to parasympathetic innervation (63).

The peripheral terminals of vagal and spinal afferents locate in mucosal layers, muscle, and in the serosal and mesenteric attachments (67). Nerve terminals in the serosa and in muscle convey mechanosensory information relevant to distension and contraction of the bowel wall. However, the afferent information conveyed by vagal and spinal mechanosensitive afferents is very different. Vagal afferents have low thresholds of activation and reach maximal responses within physiological levels of distension. In contrast, spinal afferents, although many have corresponding thresholds for activation, are able to respond beyond the physiological range and encode both physiological and noxious levels of stimulation. This different stimulus response profile is consistent with the hypothesis that vagal afferents are involved in physiological regulation while spinal afferents are responsible for mediating pain (68). However, recent evidence implicates vagal afferents both in the mediation of sensation and in the modulation of sensory experience.

\section{Spinal convergence}

The neurophysiological convergence of visceral and somatic afferent inputs to the CNS is thought to underlie referred visceral pain, where noxious stimulation of viscera triggers pain referred to somatic sites (52). Viscerosomatic convergence may occur as a result of the scarcity of visceral afferent fibres with spinal cord terminations (less than 10\%). Visceral afferent terminals also show extensive divergence and intraspinal distribution compared to cutaneous afferents (69). Because of viscerosomatic convergence, somatic injury and visceral inflammation can respectively alter central processing of visceral and somatic inputs (70). Viscerosomatic convergence also accounts for altered central nociceptive processing through sensitization of primary afferent pathways, ultimately modifying neuronal input at sites of convergence in the spinal cord or higher centres. In addition, there can be viscero-visceral convergence whereby pain from one organ is referred to another (5).

\section{Central modulation of visceral pain}

Central projections of visceral afferents entering the brain stem or the spinal cord, make synaptic connection with second order neurones that distribute visceral information throughout central neuronal 
structures (71). Vagal afferents project to the nucleus tractus solitarius (NTS) in the brainstem with cell bodies in nodose ganglion. Spinally-converging visceral afferents terminate in the dorsal horn with second order neurones projecting to higher centres through the dorsal column pathway (DC), the spinothalamic, the spinoparabrachial, and the spinoreticular tracts, depending on where the cell body of the third-order neuron is located (72). Superficial dorsal horn projections mostly form the spinoparabrachial pathway, associated with autonomic and affective responses to painful stimuli (73). Along with NTS projections from vagal afferents, spinoparabrachial projections are transmitted to limbic and cognitive higher centres including parts of the brain involved in affect, such as the amygdala, hypothalamus and periaqueductal grey (PAG) (72, 73). Vagal projections from the nucleus tractus solitarus are mainly to hypothalamic and limbic structures associated with behavioural and emotional aspects of sensory processing. For the spinothalamic tract, the 3rd order neuron is within the thalamus, which acts as the primary hub for the central pain matrix (74).

The thalamus is somatotopically organized such that noxious signals from the spinal cord are sent to specific regions of the primary somatosensory cortex for the localization of the signal. The cortical localization for visceral pain is typically less precise since the ascending signal often innervates the spinal cord at multiple levels and pain signals from visceral and somatic sources may be transmitted by the same 2nd order spinal neuron (convergence). Within the central pain matrix, the thalamus signals to brain regions that process the emotional component of the pain signal, such as the amygdala, insula, anterior cingulate cortex, hippocampus, and nucleus accumbens $(75,76)$.

In healthy individuals, activation of the central pain matrix provides the appropriate behavioral responses (unpleasant emotion, guarding, and/or immobilization of the affected site) to promote recovery and to learn avoidance to prevent future injury
(77). Descending antinociceptive brainstem pathways are also activated by the central pain matrix to decrease noxious signalling at the dorsal horn of the spinal cord by changing the excitability of the 2nd order neuron within the spinal cord $(78,79)$. Pain modulation of the central nervous system occurs via descending pathways, with multiple areas involved, e.g. the amygdala and hypothalamus. The PAG plays an important role within this pathway through its projections to the medulla, which relay descending inhibitory signals to ascending pain pathways. Another proposed mechanism arises from the nucleus raphe magnus and nucleus reticularis, which are collections of cells derived from the rostral ventromedial medulla (RVM).

This system projects to the spinal and medullary dorsal horns to modify nociceptive signals. Profound anti-nociceptive effects occur when opiates are injected into these brain regions in animal models (80).

The RVM receives input from the PAG and is thought to be a joint final relay center in a network of descending inhibitory pathways of nociception from central sites (81).

The PAG also projects to the amygdala and other cortical sites that regulate emotion. Emotional responses, stress, and anxiety are believed to play a significant role in the integration and processing of pain. Accordingly, synaptic plasticity in the amygdala was found in a rat model of visceral pain (82). Anxiety symptoms were associated with pain-induced activation of the anterior midcingulate cortex and pregenual anterior cingulate cortex, while depression scores correlated with activation of the prefrontal cortex (PFC) and cerebellar areas within IBS (83).

\section{Gut-Brain axis}

The "gut-brain axis" is a theoretical model depicting bidirectional neural pathways linking cognitive, emotional and autonomic centres in the brain to neuroendocrine centres, the enteric nervous system and the immune system. 
Bodily visceral functions (e.g. digestion, nutrient resorption, gaseous exchange, excretion) require complex regulation in which the CNS is highly integrated with the peripheral and enteric nervous systems and hormonal controls. Accordingly, altered brain-gut interactions can contribute to autonomic dysregulation of the gut and associated pain and perceptual changes in visceral disorders like IBS $(84,85)$.

\section{Chronic visceral pain mechanisms}

Distinct from the well-established protective and adaptive functions of acute pain, pain persisting beyond tissue healing is maladaptive and serves no known physiological function. In contrast to acute pain, the mechanisms involved in the development and maintenance of persistent pain are not fully understood and visceral pain complexity make this research further difficult. The study of events immediately after acute gastrointestinal diseases, like infections or inflammations, showed a number of abnormalities that can persist even after overt remission of inflammation and can be involved in the chronicization of symptoms like pain. These abnormalities include increased gut permeability, immune response, increased mucosal serotonin availability, sensitized enteric nerves and altered gut microbiota (86). Anyway, a single factor is not likely to be responsible for the several presentations of chronic visceral pain (87).

\section{Increased gut permeability}

Acute gastroenteritis produces an increase in gut permeability in all infected individuals, both adults and children. This change lasts at least 12 weeks and up to 4 years in some individuals with PI IBS. In patients with IBD-IBS mucosal permeability is markedly elevated compared with both healthy individuals and patients with IBD without IBS-like symptoms (88).

Nevertheless the increased permeability persisted even in patients whose bowel habit had returned to normal, which might indicate that increased permeability increases susceptibility to IBS symptoms but is not sufficient to cause symptoms without other factors either genetic or environmental (86).

Therefore, the increased permeability might represent a common pathway for other factors to influence the gut. An altered gut permeability imply increased exposure of the immune system to bacterial and food antigens and immune activation could further deranges barrier function as well (89). Increased gut permeability is reported in both diseasefree relatives and patients with Crohn's disease or ulcerative colitis, supporting the hypothesis of its role as a predisposing factor with many causes (90). Also, real-life stress of public thesis defence, which more closely models the stressors patients associate with exacerbation of their IBS symptoms, has been shown to increase small bowel permeability, an effect that seemed to be blocked by the mast cell stabilizer cromoglycate (91). Rat studies, which enable improved control of other variables, clearly show that permeability is increased by psychological stress (induced by water avoidance or crowding), acting via mucosal mast cells and vasoactive intestinal peptide (92). Most of these changes can be mimicked by corticotropin-releasing factor (CRF) injections and blocked by CRF antagonists in these rat models (93).

\section{Abnormal serotonin availability}

Serotonin, or 5 hydroxytryptamine ( $5 \mathrm{HT}$ ), is contained in enterochromaffin cells found in the intestinal crypts. 5 HT stimulates motility and secretion of water into the lumen (94). These effects are terminated by transport into enterocytes and neurons by the serotonin transporter (SERT), whose impairment in inflammatory conditions can lead to excess mucosal serotonin availability. Increased rectal enterochromaffin cell numbers have been reported in PI IBS after C. jejuni infection and in IBS D, associated with a tenfold increase in 5 HT release in biopsy samples, correlating with pain severity (95, 96). The striking clinical benefit of inhibiting $5 \mathrm{HT}$ 
synthesis with a THP 1 inhibitor or blocking 5 HT3 receptors with 5 HT3 receptor antagonists in IBS$\mathrm{D}$, does confirm that increased $5 \mathrm{HT}$ availability has a role in symptom generation $(97,98)$. Postprandial plasma levels of 5 HT have been found to be elevated in PI-IBS and IBS-D.

The increased levels might reflect either increased release or impaired reuptake by SERT $(99,100)$. Human studies of the role of 5 HT in IBD are more limited. Increased enteroendocrine cell numbers staining for $5 \mathrm{HT}$ and peptide YY have been seen in lymphocytic colitis.

However, both an increase and decrease in numbers of these cells have been reported in Crohn's disease and ulcerative colitis. When frank ulceration occurs, the enterochromaffin cells are destroyed, their numbers decrease and 5 HT levels fall, but increases in enterochromaffin cells can occur during intestinal regeneration, hence the confusion in the literature $(12,101,102)$.

Neural processes in the gastrointestinal tract which can be influenced by local alterations in serotonin concentrations with subsequent relay of signals along the scaffolding of the brain-gut axis to influence neurotransmission at central level (103). Abnormalities in the metabolism of the serotonin precursor, tryptophan, were found in different GI disease, including IBDS and different types of IBS, resulting in a dysregulation of serotonin synthesis. In the gut, the three major Trp metabolism pathways leading to serotonin, kynurenine, and indole derivatives are under the direct or indirect control of the microbiota.

Interesting is the ability of microbiota to control host tryptophan metabolism along the kynurenine pathway, thereby simultaneously reducing the fraction available for serotonin synthesis and increasing the production of other neuroactive metabolites $(104,105)$.

Since gut microbiota is clearly affected in both IBS and IBDs, a long-term dysregulation in serotonin metabolism due to gut dysbiosis was proposed as possible mechanism for visceral symptoms persis- tence in these patients, though there are poor evidence about this correlation (86).

\section{Dysbiosis in gut microbiota}

A growing body of preclinical and clinical evidence supports a relationship between the complexity and diversity of the microorganisms that inhabit our gut and health status.

Under normal homeostatic conditions this microbial population helps maintain intestinal peristalsis, mucosal integrity, $\mathrm{pH}$ balance, immune priming and protection against invading pathogens. Furthermore, these microbes can influence centrally regulated emotional behaviour through mechanisms including microbially derived bioactive molecules (amino acid metabolites, short-chain fatty acids, neuropeptides and neurotransmitters), mucosal immune and enteroendocrine cell activation, as well as vagal nerve stimulation. Furthermore, the gut microbiota regulates several host biochemicals with know neuromodulatory properties, including endocannabinoides, neuropeptides and biogenic animes $(85,106)$.

Post-infectious IBS (PI-IBS), which bears close resemblance to IBS-D, is a surprisingly common result of acute gastroenteritis (primarily of bacterial aetiology) with a reported incidence of between 5$32 \%$ (107). Besides, antibiotics significantly alter gut microbial ecology (namely a collapse in diversity) and disrupt interactions with host metabolism (108). A consequence of this is the frequent disturbance in bowel habit, particularly with broad-spectrum antibiotics (5-62\%), and numerous animal and human studies provide evidence of the role antibiotics play in IBS pathogenesis (109). Preclinical studies demonstrated that early life exposure to antibiotic alters microbial composition and leads to enduring effects on visceral pain of adults (110). Evidence that this also occurs in humans was shown in a prospective study in which consecutive patients prescribed antibiotics for non-GI complaints were more than three times as likely to report chronic bowel symptoms as controls (111). 
Numerous studies have shown alterations in the gut microbiota in both IBS and IBD and a large number of microbial pathways were shown to be disrupted in patients with IBD or IBS (112). However, the extent to which microbiota changes individually or collectively have a role in the aetiology of visceral pain remains unaddressed.

Gastrointestinal microbiota can stimulate the release of the body's natural pain-suppressing biomolecules including opioids from innate neutrophils and monocytes, endocannabinoids from colonic tissue as well as other pain modulators including monoamines (113-115).

In contrast to these preclinical and clinical evidence for a role for gut microbiota in visceral pain, many studies remain inconclusive with a large "non-responder" population in many probiotic trials (17).

\section{Altered gut immune response}

The GI tract has a complex innate and adaptive mucosal immune system that is capable of monitoring the luminal content for a diverse array of innocuous antigens including commensal microbiota and food antigens (oral tolerance) versus invasion of the host by potentially toxic pathogens. The immune cells that reside in the intestine mucosa, mesenteric lymph nodes, and Peyer's patches make up the gutassociated lymphoid tissue (GALT). Cells of the GALT, dendritic cell, macrophages and B-cells make up the antigen-presenting cells and shape the responses of a heterogeneous population of T cells. Such response can be tolerogenic against commensal bacterial antigens or immunogenic against invading pathogens. The maintenance of a delicate balance between tolerance and immune system activation is key for overall gut health with abnormalities in this equilibrium leading to pathologies of the gut including IBD, CD, and food intolerances (116118).

Significant increases in the number of $\mathrm{T}$ lymphocytes, macrophages and mast cells, enteroendocrine cells and IL- $1 \beta$ expression were observed in submucosal biopsies of PI-IBS patients compared with healthy volunteers (119-121).
Immune cells contribute significantly to both neuropathic and inflammatory pain: on one hand, distinct immune cell types release mediators that act on the terminals of nociceptors to drive peripheral sensitization; on the other hand, in the CNS, microglia, astrocytes and $\mathrm{T}$ cells modulate neurotransmission and spinal cord pain circuitry to drive central sensitization. In acute inflammation, pain often parallels the immune response and diminishes with resolution of inflammation. In chronic diseases such as rheumatoid arthritis and colitis, persistent immune triggers such as cytokines mediate long-lasting pain. In this regard, multiple studies have shown that cytokine and chemokine signalling pathways impact pain-like behaviours in animal models of inflammatory and neuropathic pain $(122,123)$. IL-1 $\beta$ was one of the first cytokines demonstrated to cause hyperalgesia upon both local challenge and systemic administration in mice (Ferreira et al., 1988; Fukuoka et al., 1994). Both tumor necrosis factor- $\alpha$ $(\mathrm{TNF}-\alpha)$ and interleukin-1 $\beta$ (IL-1 $\beta$ ) levels were found increased in the spinal cord of animals after the induction of colitis by TNBS. In these animals the colonic inflammation is strictly associated with the development of persistent post-inflammatory visceral hypersensitivity (124).

Besides, IL-10, a key anti-inflammatory cytokine, possesses anti-nociceptive properties $(125,126)$. IL-10-mediated suppression of pain may involve both its inhibitory effect on the expression of proalgesic cytokines such as TNF, IL- 6 and IL- $1 \beta$ and a direct effect on neurons (127). Despite this, the serum levels of either IL-5, IL-6, IL-10, and TNF- $\alpha$ were found significantly higher in patients with IBS compared to healthy controls $(128,129)$. In rats, a similar colon pattern of cytokine mRNA levels was observed in the post-inflammatory phase of colitis: higher IL-6 and IL-10 and no modifications of TNF- production (130).

Gram-negative bacterial infections are also frequently painful. LPS, which is a major component of Gram-negative bacterial cell walls, induces pain when injected into mice. LPS can directly act on nociceptors, as nociceptors express Toll-like receptor 
4 (TLR4), which mediates LPS detection (131) and LPS-induced systemic immune activation leads to visceral hyperalgesia in rats (132). In accordance, TLR4 blockage counteracted visceral hyperalgesia associated to a high-fat diet in mice (133).

The increased numbers of $\mathrm{T}$ and mast cells in mucosal biopsies of IBS patients significantly correlated with abdominal bloating frequency and symptoms of dysmotility-like dyspepsia (134). In addition, mast cells were found to be located in closer proximity to nerve fibers in IBS patients vs controls while the number of mast cells in close proximity to nerves significantly correlated with the severity and frequency of abdominal pain and discomfort (135). Yet, nociceptor interactions with neutrophils have been less well characterized, but recent studies show a key role for nociceptors in regulating neutrophil recruitment and activation (136). A tight interplay between nociceptors and mast cells has long been postulated owing to their anatomic co-localization. Mast cells are found in close apposition to nerve fibres in barrier tissues, particularly CGRPand substance $\mathrm{P}+$ neurons $(137,138)$. Increases in the number of nerves-mast cell contacts have been reported in models of inflammatory and allergic diseases, as well as in parasitic infection of the colon. Like mast cells, dendritic cells (DCs) have been found to be in close contact with nociceptors in peripheral tissues. Indeed, nociceptor regulation of DCs has an important role in modulating immunity $(139,140)$.

Although the evidence for aberrant immune activation seems overwhelming in PI-IBS, care must be taken when interpreting these results as the evidence supporting persistent immune cell infiltration or low-grade inflammation in IBS is conflicting. Indeed, various research groups found no differences in immune cell numbers or cytokine mRNA expression in mucosal biopsies of PI-IBS and IBS patients compared with healthy volunteers $(141,142)$.

Braak et al. even reported decreased numbers of mast cells, macrophages and $\mathrm{T}$ cells in the colonic mucosa of IBS patients compared with healthy vol- untaries (141). Also, at mRNA level, decreased levels of genes linked to chemokine function or IL-10 were detected among IBS patients (143). More recently, Bennet et al. found no differences in cytokine mRNA expression levels in sigmoid colon biopsies when analysing IBS patients vs healthy volunteers (142). These reports, which fail to demonstrate immune infiltration in the colorectal mucosa of PI-IBS patients, also fail to demonstrate a correlation between immune infiltration and visceral pain perception (141).

\section{Altered nervous signalling}

Acute inflammation damages enteric nerves and disconnects them from their gut targets. As nerves regrow, they sprout and subsequently undergo complex remodelling in the process of reconnecting with their targets. This process has been clearly described in experimental model of colitis $(144,145)$. In the enteric nervous system, inflammation causes a rapid loss of enteric neurons and viscera-fugal neurons. Of the remaining enteric neurons, specific subpopulations located in the myenteric and submucosal ganglia become hyperexcitable and synaptic transmission between them is facilitated. These changes in neuronal function result in decreased secretion and disrupted motility (146). In the prevertebral ganglia, although synaptic input from viscerafugal neurons is reduced, sympathetic viscera-motor neurons are actually hyperexcitable. Many of the neuronal changes evident during inflammation are still present after resolution of inflammation, with hyperexcitable enteric neurons and facilitated synaptic transmission still evident in the post-inflammatory state. This hyperexcitability results in increased neuronal activation in the nucleus of the solitary tract or the dorsal horn of the spinal cord, respectively $(86,146)$. In whole-animal studies, this process translates to enhanced pain responses to either gastric or colorectal distension.

In this context, an increased density of colonic afferent central terminals was also observed, as there is a sprouting of these terminals into different re- 
gions of the dorsal horn of the spinal cord.

This plasticity results in increased numbers of dorsal horn neurons in the spinal cord being activated in response to noxious colorectal distension. Many of these changes are still present or are even enhanced following resolution of inflammation (147). Current theories suggest that neuronal plasticity involving the sensitization of visceral afferent sensory nerve fibers and broad alterations to the brain-gut axis contribute to the development of chronic abdominal pain. Much of this theory is based on evidence demonstrating changes in neuronal sensitivity, firing patterns, and network activity in the periphery, brain, and spinal cord. Although little is still known regarding the mechanisms that drive these alterations to neurons and their networks, it is increasingly clear that these properties are regulated by glia (18).

\section{Peripheral and central glia activation}

Glia (from Greek $\gamma \lambda$ oí $\alpha$ meaning "glue") pertains to non-neuronal cells in the central (CNS) and peripheral nervous system (PNS) that nourish neurons and maintain homeostasis. In addition, glia is now increasingly appreciated as active regulators of numerous physiological processes initially considered exclusively under neuronal regulation (148). The intricate molecular mechanisms that govern gliamediated regulation are beginning to be discovered, but much remains unknown about the functions of enteric glia in health and disease.

In the gut, multiple distinct types of glial cells, encompassed by the term "enteric glia" (EGCs) are known to modulate enteric neuron function $(18,58)$. Enteric glia forms a cellular and molecular bridge between enteric nerves, entero-endocrine cells, immune cells, and epithelial cells, depending on their location and its function can be profoundly changed by many factors, such as pro-inflammatory cytokines, bacteria, and neurotransmitters (149).

Thus, EGCs may undergo dynamic processing under pathological conditions and serve overlapping functions such as modulating intestinal barrier func- tion, mucosal immunity and enteric neurotransmission via releasing various substances (150). Reactive enteric glia, as with reactive astrocytes, display a marked hypertrophy, increased proliferation and vary expression of both cytoplasmic and surface proteins under certain conditions (148). Notably, under pathological conditions, enteric glia can transform into antigen-presenting cells that promote inflammation by attracting immune cells.

Moreover, enteric glia can modulate enteric neural circuits in a number of ways, including terminating the actions of neurotransmitters from synapses, supplying neurons with neurotransmitter precursors and by generating neuroactive substances $(149,151)$. Recently, a research group in Chicago demonstrated that the intestinal inflammation alters the ENS functionality by affecting the interaction between enteric neurons, nociceptors and glia. In that context the activation of enteric glia resulted to be actively involved in visceral hypersensitivity (152). Interestingly glia activation, triggered by the intestinal damage, persists even in the remission phase of colitis (153), spreading vertically to the dorsal root ganglion where it was found an increased coupling between satellite cells and neuron that was positively correlated with visceral pain $(154,155)$. This upward activation of glia along the sensitive pathways would suggest an involvement of central glia in the persistence of pain after the peripheral damage resolution. It is now acknowledged that the development of central sensitization engages not only neuronal, but also glial processes (156). Within the CNS, glia is the non-neuronal, immune-like cell population that constitute the vast majority of cells. Glia comprises satellite glial cells in the ganglia, and microglia, astrocytes and oligodendrocytes within the spinal cord and brain. The anatomical co-localization of astrocytes and microglia in the spinal cord, combined with pre- and postsynaptic neurons, forms a key site of interaction termed the "tetrapartite synapse" (157). In this context, the reactivity state and control of astrocytes and microglia is critical in maintaining healthy CNS 
activity. Many of the proinflammatory responses of glia are important in protecting against challenges that disrupt the homeostatic balance of the CNS (158). However, under certain conditions, glial reactivity is not advantageous and can instead be detrimental to neuronal function, such as during the manifestation of persistent pain. In response to strong or persistent receptor stimulation, microglia switch from a surveillance state to an active response state, and astrocytes transition from a regulatory to reactive state (159).

Moreover, proinflammatory mediators and glial-derived neurotransmitters can reciprocally stimulate glia in an autocrine and paracrine manner, thereby amplifying a positive feedback loop of unfavorable activity (160-162). Glial proliferation, morphological changes and increases in protein expression can persist for months after initial injury, even beyond tissue healing $(163,164)$. Under these circumstances, the release of proinflammatory mediators by glia can contribute to ongoing nociception, by inducing long-lasting plastic changes of synaptic connectivity that enhances the transmission of ascending nociceptive information $(165,166)$.

Many studies are also investigating the impact of early-life stressors, such as maternal separation or injury, on long-lasting glial alterations in the adult. Such events can be the 'first hit' that primes glia to over-respond and be detrimental in restoring 'second hit' immune challenges later in life. The hypothesis is that adverse life events provoking longterm heightened glial reactivity may lead to greater sensitivity to future harmful stimuli. Priming of spinal glia may also provide an explanation for why some people are predisposed to developing IBS as result of gastrointestinal inflammatory or infections. In fact, the initial scenario of gastroenteritis preceding IBS could represent the 'first hit' of irritation that sensitizes the neuroimmune system, later contributing to disease progression.

The relevance of inflammation in glia priming could also explain why IBS symptoms were reported in $\sim 40 \%$ of patients with IBDs in apparent remission (23).
The studies on glia and IBD employed rodent models of di- or trinitrobenzene sulfonic acid-induced colitis and chronic pancreatitis. In these preclinical models, marked increases in reactivity were described for microglia in the spinal cord and hippocampus, and activated satellite glia in the dorsal root ganglia. This is associated with an upregulation of TNF $\alpha$ levels, and closer apposition between satellite glial cells and primary afferent neurons in the dorsal root ganglia via enhanced neuron-glia gap junction coupling. Microglia activation was associated with an increased visceromotor reflex activity and abdominal withdrawal reflex to graded colonic distension. Intracerebroventricular, intrathecal or systemic minocycline (a microglia inhibitor) or intrathecal administration of an anti-TNF $\alpha$ antibody attenuated pain behaviors in these animals (167169).

In support of the direct involvement of microglia in visceral pain, the injection of fractalkine (a microglia activator) reproduced the visceral nociception in naïve rats (125). Unlike microglia, the role of spinal astrocytes in visceral pain has been poorly investigated, though both these cell types were found activated in chronic pain conditions $(170,171)$.

In summary, heightened spinal glial reactivity and proinflammatory signalling may contribute to ongoing peripheral inflammation, as well as enhancing pain by central sensitization. This raises another interesting question as to whether centrally derived neurogenic inflammation, generated in part by neuroimmune signalling, contributes to the perpetuation of other inflammatory diseases. Indeed, neurogenic inflammatory processes have been implicated in the exacerbation of IBD, cystitis and endometriosis. In this setting, enhanced afferent signalling in response to the tissue insult may facilitate lesion development by a positive feedback loop (156). Although the link between glia activation and visceral pain persistence has to be further clarified, these preliminary results support the pro-nociceptive role of glia in mediating visceral hyperalgesia and make it a promising target for controlling chronic visceral pain. 


\section{Stress}

While the previous description was presented as a "bottom-up" model of sensitization leading to chronic visceral pain, direct sensitization of the central pain matrix can drive a "top-down" mechanism wherein stress and negative emotions can promote enhanced perception of nociception in the absence of overt peripheral injury $(172,173)$. The body's response to stress is composed of two parallel systems: the quick "flight or fight" of the sympathomedullary axis and the slower hypothalamic-pituitary-adrenal (HPA) axis.

The sympathetic response to acute stress mobilizes epinephrine and norepinephrine to change bloodflow away from the skin and GI tract toward the muscles along with providing a burst of energy and a dampening of pain perception to allow the individual to run or fight for survival.

The neuroendocrine response mediated by the HPA axis causes release of cortisol in humans or corticosterone in rodents (CORT) to mobilize glucose reserves to restore homeostasis after an acute stressor, or to cause long-term changes in metabolic function and neuronal sensitivity following chronic stressors.

Typically, the sympathetic response will habituate to repeated stressors, whereas the HPA response may or may not habituate depending on the type, duration, and variability of the stressor (174).

In addition to its metabolic functions, CORT binding to its high affinity mineralocorticoid receptor and low affinity glucocorticoid receptor (GR) within brain regions such as the hippocampus, the paraventricular nucleus of the hypothalamus, and some cortical regions induces negative feedback to terminate the response of the HPA axis, while binding at the amygdala opposes the feedback inhibition by increasing $\mathrm{CRH}$ expression and facilitation of the stress axis (175-177).

The central nucleus of the amygdala $(\mathrm{CeA})$ integrates viscerosensory signaling with neuroendocrine and autonomic responses to stressors and is primed to influence both stress and pain signalling
$(178,179)$. Exposure to chronic stress causes neuronal remodelling in specific regions and the net effect of this neuronal remodelling is the exacerbation of pain perception and the promotion of chronic pain symptomatology due to the loss of anti-nociceptive and anti-stress signalling within the central pain matrix combined with facilitation of nociceptive and stress-responsive signalling. These remodelled pain circuits also impinge on the function of key brainstem regions that modulate descending pain inhibition (174). Clinically, the effect of chronic stress on visceral pain is best illustrated by the high co-morbidity of anxiety, depression, and other psychiatric disorders with functional pain disorders, such as IBS $(180,181)$. Multiple rodent models of stress showed an increase in plasma CORT resembling that seen in IBS patients and, concurrently, an increase in visceral sensitivity (182-184). Preclinical studies in rodent models of early-life stress have provided important experimental evidence to suggest that brain circuits are primed by exposure to stress or pain during early life, predisposing individuals to chronic pain disorders as adults (174).

\section{Genetic predisposition}

The understanding of IBS genetics lags far behind, although there are a number of initiatives such as the international network GENIEUR (Genes in Irritable Bowel Syndrome Europe; https://genieur.eu/) aiming to improve the phenotyping and power of future studies. Most studies have been investigations of candidate genes and have been underpowered (185).

A meta-analysis did support the link between IBS and polymorphisms in the TNFSF15 gene, a member of the TNF superfamily that influences interferon production (185-187). This gene was found to be a risk factor for Crohn's disease (188), supporting the idea that an excessive response to immune stimulation could predispose to both IBD and IBS. However, the same IBS study that showed the link with TNFSF15 found no association with 30 other 
IBD genes, reinforcing the argument that IBD requires other less common factors than are required for IBS (187), and explaining why IBS is 100 times more prevalent than IBD (189).

\section{Visceral pain therapy}

Chronic pain management still contributes significantly to a large segment of healthcare resource consumption and have a considerable negative impact on lives with psychological distress, disturbance of work and sleep and sexual dysfunction (190).

For this reason, pain is now regarded as a syndrome, rather than a symptom or by-product of illness (81). Patients with chronic visceral pain present unique challenges because their pain has often a complex nature associated with strong autonomic reactions and changes in visceral function (191).

Since IBS symptoms do not have an apparent structural or biochemical explanation, the therapy included psychotherapy-behavioural therapy, nutrition and drug treatment of the predominant symptoms (bulking agents, antidiarrheals, antispasmodics and tricyclic antidepressants). Currently, the most efficacious therapies against visceral hypersensitivity are mainly directed to treat bowel dysfunction, though effects on visceral function can exacerbate the pain or lead to additional discomfort, while drugs able to directly target the related pain are still unsatisfactory $(25,191)$. Based on the clinical overlap between IBD and IBS, with IBS-like symptoms frequently reported in patients before the diagnosis of IBD, and a higher than expected percentage reports of IBS symptoms in patients in remission from established IBD, the therapeutic approach for IBD and IBS pain relieving is often the same $(19,58)$.

\section{Dietary interventions}

Food is often a trigger of abdominal symptoms in patients with IBS $(192,193)$. In relation to colonic function, these triggers include stimulation of co- lonic motility through a vagally mediated reflex, inhibition of colonic water absorption and stimulation of colonic transit and high amplitude propagated contractions by carbohydrates that reach the colon and their metabolic products. On the other hand, deficiency of fibre in the diet is often considered as a factor predisposing to constipation, which may then cause abdominal pain (194).

A number of different diets are now promoted to treat IBS symptoms, and these include regimens that exclude carbohydrates, fermentable foods, gluten, and substances that might create food-related antibodies. The more commonly employed by patients are diets low in Fermentable Oligo-, Di-, Mono-saccharides And Polyols (FODMAPs) and excluding gluten (25). There are numerous evidences that the intake of FODMAPs is associated with development of symptoms of IBS, including pain. The proposed mechanisms include increasing water retention in the small intestine through the osmotic effects of the molecular entities and rapid fermentation by intestinal bacteria, leading to production of gas and short chain fatty acids with luminal distension resulting in sensations of pain and bloating and stimulation of abnormal motility (195).

The low-FODMAP diet intervention for IBS patients consists of 3 distinct phases: the restriction or elimination phase, the re-introduction or re-challenge phase, and the maintenance or personalized phase $(196,197)$. During the initial phase, patients eliminate FODMAPs from their diets. Importantly, the low-FODMAP diet is meant to last only 4 to 6 weeks, and it is essentially a method to determine whether symptoms are related to specific foods. It is not designed for long-term use. During the second phase, after no symptom improvement or resolution, foods containing FODMAPs are reintroduced gradually, with the goal of identifying tolerance to individual ingredients and specific symptom triggers among fermentable carbohydrates. This phase lasts several weeks, if not longer, as foods are slowly reintroduced. After reviewing and interpreting results from the food re-challenge phase, the go- 
als of the third phase are to continue the intake of foods that were well-tolerated and to restrict foods that produced symptoms. As the tolerance to different FODMAPs can change over time, patients can attempt to reintroduce their trigger foods a few months after symptom control if they so desire (198). Systematic review and meta-analysis have documented the greater benefit of low FODMAPs diet over control treatment for overall symptom severity and severity of abdominal pain and bloating (198-200). The mechanism of benefit is assumed to relate to reduced colonic fermentation or greater microbial diversity and reduced total bacterial abundance $(196,197,201)$. Nevertheless, the low FODMAP diet remains controversial, and it still presents short-term and long-term limitations, including a high level of restriction that may be required in individual patients, the need for monitoring by an expert dietician, potential for developing nutritional deficiencies, potential for changes in gut microbiota, lack of predictors of response as well as relative efficacy compared with other dietary, psychological or pharmacological interventions for IBS (202).

Even the elimination of gluten from the diet of IBS patients showed an efficacy beyond patients with celiac disease $(203,204)$.

To this point, a large meta-analysis reviewing 1726 studies evaluating the efficacy of a gluten-free diet on the management of IBS recently found insufficient evidence to recommend this diet for IBS symptoms, as findings were not statistically significant (205).

\section{Pro- and Prebiotics supplementation}

The World Health Organisation define probiotics as "live microorganisms, which when taken in adequate amounts, confer a health benefit on the host". Probiotics, derived from the Latin "for life", have been used in fermented foods for millennia. Probiotics may exert their beneficial effects on the host through various mechanisms: (1) Pathogen suppression - competition for nutrients and mucosal space, and the production of bacteriocins (anti-bacterial proteinaceous toxins); (2) Improvement of barrier function - tight junction (spaces between adjacent epithelial cells) homeostasis; (3) Immunomodulation - pathogen-associated molecular patterns (PAMPs) are sensed by dendritic cells which influence B and T cell regulation; and (4) Neurotransmitter production - a number of lactic acid bacteria are capable of producing serotonin and gamma-aminobutyric acid (GABA) which may influence the communication between the gut and brain (gut-brain axis) (206).

Moreover, some probiotics strains, coined "psychobiotics", seem to be capable of conferring mental health benefits through interactions with commensal gut bacteria. These psychophysiological benefits include effects on emotional and cognitive processes, systemic effects on the hypothalamic-pituitary-adrenal axis, and neural effects via neurotransmitters and neurotrophic proteins, mechanisms which are often affected in IBS patients $(207,208)$. The latest consensus definition of prebiotics by the International Scientific Association for Probiotics and Prebiotics defines them as "a substrate that is selectively utilised by host microorganisms conferring a health benefit" (209). Prebiotics such as inulin and inositol are found in foods including leeks, asparagus, Jerusalem artichokes, garlic, and onions (210). Some of the most common prebiotics are inulin, $\beta$-glucan and fructooligosaccharides (FOSs) (211-213).

Synbiotics are products containing both prebiotics and probiotics, whereby they act synergistically. In a synbiotic, the prebiotic component is designed to selectively stimulate either growth or metabolism by the probiotic bacteria and may therefore be considered for use where there may be survival challenges for the probiotic alone. In addition, they may also stimulate certain commensal bacteria in the GI tract $(214,215)$. The interactions between the gut microbiota, stress and the central nervous system have emerged suggesting that visceral pain-related disorders may be candidates for symptom relief through therapeutic alterations of the microbiome (216). Several preclinical studies suggest that therapeutic interventions that alter the microbiome may have 
beneficial effects on visceral pain induced by stressor of gut inflammatory processes (217-221). However, recent randomised controlled trials demonstrated no significant benefit of probiotics preparations over placebo in the treatment of pain in adults with IBS in contrast to the benefit observed in some (but not all) trials in children with regard to frequency and intensity of abdominal pain (222224). Thus, further studies are required to address which bacterial strains and which patients are most likely to respond. However, in vitro a multi-strain challenge resulted in a greater reduction of inflammation-modulated genes in comparison to singlestrains, indicating a synergistic effect of bacterial combinations which reinforces the rationale for using multi-strain probiotic formulations (225). Considering the advantages of combining multiple strains in respect to the use of a single bacterial strain, it is natural to question whether the transfer of a whole healthy microbiota could bring even more benefits.

Faecal Microbiota Transplantation (FMT), also called faecal bacteriotherapy or stool/faecal transplantation, is the infusion or engraftment of liquid filtrate faeces from a healthy donor into the gut of a recipient (226). To date FMT is approved only for the therapy of Clostridium difficile infection, where the microbiota transplant is highly efficacious with the ability to restore healthy microbial ecology. The same efficacy has not been achieved when FMT is employed for the treatment of other diseases (227). Current evidences from randomized clinical trials do not suggest a benefit of FMT for global IBS symptoms, though there remain discrepant results among the trials (228).

\section{Non-absorbed antibiotic, rifaximin}

Rifaximin produced significant improvements in core symptoms of IBS-D in patients treated with up to three 2-week courses of therapy. With second repeat treatment, the most significant benefit was the relief of urgency and bloating, with borderline benefit on abdominal pain and stool consistency (229, 230). The mechanism of benefit of rifaximin is still unclear. In the past, it was assumed that the benefit reflected beneficial effects on small bowel bacterial overgrowth or direct anti-inflammatory actions that countered effects of bacterial products (231). A recent study appraised several potential mechanisms of action of rifaximin in the treatment of non-constipated patients with IBS, including permeability, expression of barrier proteins and faecal microbiome, but there were no significant effects relative to placebo (232).

\section{Antispasmodics}

In addition to visceral hypersensitivity, abnormal GI motility is recognised as an important pathophysiological mechanism. Increased or decreased GI transit is indeed reported in IBS-D and IBS-C, respectively (233).

A European systematic review, focusing on nine placebo-controlled studies of antispasmodics in IBS, concluded that there is level II evidence suggesting that antispasmodics may improve abdominal pain, but that there is lack of evidence to support global symptom improvement (234). Afterwards, a Cochrane review concluded that there was weak evidence for the benefit of some antispasmodics for abdominal pain and global symptom relief, although it was unclear which individual classes were effective (235).

Among the antispasmodics, the strongest data were for otilonium bromide.

This compound targets L-type and T-type calcium channels, and muscarinic type 2 and tachykinin neurokinin (NK)-2 receptors, possibly contributing to its increased efficacy. The efficacy of otilonium bromide in IBS has been confirmed in clinical studies, including significant improvement of abdominal pain and bloating severity with otilonium bromide versus placebo, or reduction in the number of pain episodes and severity of abdominal distension (236).

Antispasmodics are generally well tolerated, apart from anticholinergics which can cause atropine-like side effects, including constipation (237). Peppermint oil and its active ingredient, 1-menthol, are also 
widely investigated in medicinal preparations for global improvement of IBS symptoms $(238,239)$. Indeed, they are smooth muscle calcium channel antagonists that may cause muscle relaxation and, therefore, serve as an antispasmodic. Also they have $\kappa$-opioid agonistic properties that may alter gut sensitivity, have been reported to possess anti-inflammatory effects and have serotonergic (5-HT3) antagonistic properties $(240,241)$.

Recent evidence has indicated that menthol-induced analgesia is mediated by activation of the temperature sensing ion channel, transient receptor potential ion channel melastatin subtype 8 (TRPM8) (242). TRPM8 has been identified on colonic nerve fibres as well as on colonic DRG neurons, where it showed antinociceptive properties (243). Visceral hypersensitivity has been relieved in rat by a combination of essential oils from peppermint and caraway. In this effect seems involved mycobiome modulation (244).

\section{Serotonin receptors modulation}

The role of 5-HT in GI motility and pain perception is rather complex, and intervention in the 5-HT signalling pathway may, therefore, impact several mechanisms involved in IBS symptoms, including pain. 5-HT released from EC cells may affect several subtypes of enteric neurones (intrinsic and extrinsic sensory neurones as well as motor and secretomotor neurones) and final effector cells (smooth muscle cells and enterocytes) (245). 5-HT4 stimulation with agonists potentiates peristalsis and is therefore useful in constipation predominant form of IBS and in chronic constipation. In addition, the partial 5-HT4 agonist, tegaserod, has been proposed to reduce visceral sensitivity by inhibiting substance $\mathrm{P}$ expression in the dorsal horn of spinal cord (246). Tegaserod relieves global IBS symptoms as well as individual symptoms of abdominal discomfort, number of bowel movements and stool consistency (247). One important aspect of partial agonists is that they may surrogate the functions of 5HT when its release is impaired but may work as antagonists by opposing the effect of endogenous 5-
HT (which is a full agonist) in case of 5-HT overload. In addition, partial agonists may help to overcome, at least in part, the problem of 5-HT4 receptor desensitisation. Noteworthy, 5-HT4 receptors are present in human atrial cells and when stimulated may cause atrial arrhythmias (248). Indeed, tegaserod was pulled out of the market by because of the risk of heart attacks and strokes. Recently, FDA approved the reintroduction of Zelnorm (tegaserod) for the treatment of IBS-C, but with some restrictions (FDA, 2018).

On the other hand, 5-HT3 antagonists (alosetron and cilansetron) prevent the activation of 5-HT3 receptors on extrinsic afferent neurons and can decrease the visceral pain associated with IBS (97). These agents also retard small intestinal and colonic transit and are therefore useful in diarrhea-predominant IBS. Several randomized, controlled trials have shown that alosetron relieves pain, improves bowel function, and provides global symptom improvement in women with diarrhea-predominant irritable bowel syndrome. However, ischemic colitis and severe complications of constipation lead to the withdrawal of alosetron from the market followed by remarketing with a comprehensive risk management program (249).

\section{Antidepressants}

Visceral pain syndromes, including IBS, can be effectively treated by a variety of therapies that modulate the interactions between the central and enteric nervous systems, as antidepressants (250). Tricyclic antidepressants (TCA) are the first-line pharmacologic treatment for symptom improvement in gut-brain axis disorders where pain is a prominent feature.

Their mode of action is by 5-HT and NA reuptake inhibition in combination with additional receptor antagonistic properties (5-HT2A and 2C, muscarinic1, histamine1).

There are slight variations comparing different TCAs from these aspects where the tertiary amines (amitriptyline, imipramine) are more prone to produce side effects from their greater antimuscarinic 
and antihistaminic actions compared to the secondary amines (desipramine, nortriptyline). These side effects, particularly sedation and constipation, can be used also to treat some aspects of IBS such as sleep disturbance and diarrhoea, if present. it was also shown that escitalopram, an SSRI, did not have the same positive effect on abdominal pain as TCAs. Anyway, it is important to consider that potential benefit with higher dosages of TCAs (particularly the tertiary amine agents) is compromised by their greater potential for side effects (251).

Preclinical and clinical evidence indicate that antidepressants may have even a beneficial effect on IBD course, given that psychological factors play an important role in IBD activity and antidepressants have been reported to have also anti-inflammatory properties $(36,252)$.

The recent literature is questioning whether antidepressants are safe drugs when used over the long term for non-psychiatric indications, but several confounding factors may influence this link (eg, severity of depression and other psychiatric comorbidities) and causality has not been proven (253).

\section{Secretagogues}

The chloride channel activator, lubiprostone, is a medication used in the management of chronic idiopathic constipation as well as irritable bowel syndrome associated with constipation wherein it shows consistent benefits for bowel function and pain scores (254). Other drugs belonging to the class of secretagogues, like guanylate cyclase-C (GC-C) receptor agonists, have proven to be visceral analgesic (255). The analgesic properties are mediated by a cascade of intracellular events starting with GC-C stimulation that gives rise to intracellular cyclic guanosine monophosphate (cGMP) production; cGMP transported to the extracellular space modulates the conduction properties of nociceptive neurons located in the submucosa. This concept is based on mechanistic studies in animal models and has been shown to be relevant in the treatment of the pain component of IBS (256-258). Since fluid excretion results in an accelerated gut transit, GC-C stimulation-based therapies are restricted to those patients with a bowel habit dominated by constipation.

Linaclotide was the first substance available for clinical use after proving to be effective in IBS-C, followed by plecanatide that is available at some markets with the same indication (259-261).

\section{Peripheral Opioid Receptor modulation}

Stimulation of the visceral $\mu$-receptor has for long been the first-line treatment option in conditions involving chronic diarrhea, including IBS-D. From the historical use of opioids with both peripheral and central effects, the advent of loperamide, a $\mu$ receptor agonist that does not penetrate the bloodbrain barrier was a major break-through. One limiting factor has been that a substantial proportion of patients do not tolerate this treatment due to the development or aggravation of abdominal pain or constipation. Therefore, $\mu$-opioid agonists use is limited to the acute treatment of pain exacerbations in patients with IBS (262). A new therapeutic option, eluxadoline, has agonistic properties on $\mu$ - and $\kappa$ receptors, and antagonistic properties on $\delta$-receptors. Animal studies showed promise that eluxadoline could reduce visceral hypersensitivity and normalize transit in diarrhea models where the combined $\mu$ - and $\delta$ - receptor effects normalized transit over a wider dose range compared with loperamide (263-265).

The adverse events of pancreatitis and sphincter of Oddi spasm led to specific exclusions of patients with a history of bile duct obstruction, pancreatitis, severe liver impairment or severe constipation, and in patients who drink more than three alcoholic beverages per day (FDA report, 2016).

\section{Gabapentenoids}

Gabapentenoids agents, pregabalin and gabapentin, are ligands of the auxiliary $\alpha 2 \delta$ subunit of voltagedependent calcium channels, reducing depolarisation-induced calcium influx at nerve terminals and the consequent release of several excitatory neurotransmitters including glutamate, noradrenaline, 
substance $\mathrm{P}$ and calcitonin gene-related peptide, which are involved in pain mechanisms (266). Prevention of neurotransmitter release by pregabalin and gabapentin occurs only in pathologic states when calcium channels are being up-regulated and activated.

Albeit pregabalin and gabapentin are predominantly central acting analgesic (267), they also improve bowel compliance to distention perhaps through blocking calcium channels activity in smooth muscle (268). Gabapentinoids have been shown to reduce visceral hypersensitivity in experimental animals $(269,270)$.

In humans gabapentenoids were reported to generally improve IBS symptoms, though pregabalin, tested in pharmacodynamics studies in healthy controls and in patients with IBS, showed inconsistent effects on colonic compliance and sensation thresholds $(271,272)$

\section{Histamine receptor antagonist}

Mast cells and their mediators, in particular histamine, serotonin and proteases, are increasingly recognised as contributing to the pathogenesis of IBS (25). Yet, it has been found a significant correlation between mast cell density and pain perception in patients with IBD who were in remission $(273,274)$. $\mathrm{H} 4$ and $\mathrm{H} 1$ receptor antagonists dose-dependently reduce and even normalise post-inflammatory visceral hypersensitivity via different underlying mechanisms but with a synergistic effect (275).

The mast cell stabiliser, ketotifen, was tested in a prior single-centre trial where it reduced global IBS symptoms and severe abdominal pain in IBS patients (276). The potential unblinding resulting from sedating effects of ketotifen raised questions about its therapeutic potential. As ketotifen also possesses HRH1 antagonistic properties and HRH1 has been implicated in visceral hypersensitivity, a follow-up study evaluating the HRH1 antagonist, ebastine, indeed showed a significant improvement in global relief and abdominal pain (277). Ebastine is a second generation H1R antagonist free of any significant influence on the central nervous system as it does not penetrate the blood-brain barrier. Of interest, a recent study detected histamine levels changes in urine samples of patients with IBS that were modulated by a low FODMAP diet.

Thus, detection of histamine in urine or other samples may represent an interesting approach to select patients responding to HRH1 antagonists (197).

\section{NK receptor antagonists}

Sensitization of the primary afferents has been shown to occur via changes in the intrinsic properties of sensory neurons that regulate excitability and in gene expression for nociceptive-specific membrane proteins (278). Peripheral sensitization resulting from prolonged periods of stimulation releases at least two central neural mediators, glutamate and substance P (SP) that increase the efficacy of synaptic transmission between primary afferents and spinal neurons (central sensitization) (279).

NK1 and NK2 receptors are abundantly expressed in the GI tract and mediate robust and long-lasting contractions of smooth muscle in the gut. Inflammation of viscera increases central and peripheral NK1 receptor expression, and visceral hyperalgesia is attenuated in NK1 receptor knockout mice. Receptor antagonists act peripherally and centrally to attenuate viscera motor responses induced by colorectal distention. Also, NK2 receptor activation is involved in stimulation of sensory nerves and activation of visceral reflexes. Based on these characteristics, NK2 receptor antagonists have been evaluated as treatments for IBS. In a phase II, dose-finding study, ibodutant, a highly selective NK2 antagonist with high oral bioavailability, revealed improvement in patients with IBS-D (280). A more recent multinational, double-blind, placebo-controlled study showed dose-dependent improvement of overall symptoms, abdominal pain and stool pattern in IBS-D in females, but not in males. The tolerability of the compound was reported to be excellent (281). Like SP, also glutammate has a clear role in nociceptive systems, though specific relevance of this neurotrasmitter in visceral pain systems are yet to be precisely defined (279). 
Emerging pharmacological targets in visceral pain management

As argued in the previous paragraphs, the mechanisms underlying pathophysiological events that produce chronic visceral pain are still poorly understood, so therapeutic targets for treating visceral pain provide a very active and rapidly changing field of research (25). Several chemical and molecular factors in the intestine have a potentially significant role in IBS.

Between the channels in the enteric nervous system, ASICs and KCQN result particularly important. The activation of acid sensing ion channels (ASICs) which respond to decreases in $\mathrm{pH}$ can also contribute to mechanic-sensation from viscera. In the GI tract, ASIC1a has an inhibitory effect, ASIC2 has mixed effects and ASIC3 appears excitatory (282). Voltage-gated potassium channels are required for action potential firing and are also involved in spontaneous trains of action potentials after nervous system injury. Particularly KCNQ (Kv7) channels came into focus because of the anti-nociceptive effect of the specific KCNQ opener retigabine in animal models of neuropathic and visceral pain (283285).

Pain sensation is also known to be greatly influenced by different grow factors. In the colon the over-expression of brain-derived neurotrophic factor (BDNF) has been associated with abdominal pain in patients with IBS. Accordingly, TrkB (BDNF receptor), or BDNF knockdown significantly suppressed visceral hypersensitivity in mice (150). Besides, the glial cell line-derived neurotrophic factor (GDNF) family ligands resulted able to support survival, regeneration and functioning of several neuronal populations: dopaminergic, enteric, sympathetic, parasympathetic, motor, cholinergic neurons and of sensory neurons (286).

In the field of pain even the interest in Vascular Endothelial Growth Factor (VEGF) is rapidly increasing. Its instillation into the mouse bladder promotes a significant increase in peripheral nerve density together with alterations in bladder function and visceral sensitivity.

The VEGF pathway is being proposed as a key modulator of neural plasticity in the pelvis and enhanced VEGF content may be associated with visceral hyperalgesia, abdominal discomfort, and/or pelvic pain (287).

In the GI tract, another class of receptors highly studied belong to the family of protease-activated receptors (PARs). PARs are expressed both on the apical and basolateral sides of intestinal epithelial cells, these receptors might be activated both by luminal proteases (including microbial proteases) and by tissue proteases. PAR activation was reported to cause visceral hypersensitivity, modifies intestinal motility and intestinal epithelial permeability, events which take an important part in IBS symptoms generation (288).

Endogenous protease seems also to have a relevant role in the crosstalk between neurons and T cells in the modulation of neuropathic pain (289).

Recently, a study demonstrated that proteases, through the activation of PAR2, were able to induce the release of TRPV4 endogenous agonists, which were found up-regulated in tissues from patients with IBS (290). Besides, the nociceptor transient reporter potential channel V1 (TRPV1) can be sensitized by histamine contributing to visceral hypersensitivity in animals (291). According to these evidence thermosensive ion channels, TRPV1 and TRPA1, resulted implicated previously in visceral mechanosensation $(292,293)$. Interestingly, unlike other proteases, elastase effects seem to involve another type of receptor, the toll-like receptor- 4 , but the exact mechanism is still unknown (290). Tolllike receptors (TLRs) are critical pattern recognition molecules of the innate immune system. Interestingly, innate immune receptor expression resulted changed in the gastrointestinal tract of animals with stress induced IBS-like symptoms (294). Growing evidence suggests that, in IBS, the epithe- 
lial barrier, gut microbiota, food antigens and bile acids elicit abnormal responses in the key regulators of sensorimotor functions, involving the hypothalamus-pituitary-adrenal (HPA) axis. Corticotropin releasing factor $(\mathrm{CRF})$ receptor mediate the stress response, activating the hypothalamic-pituitary-adrenal and sympathic-adrenal axes. In animals both acute stress, colitis or central CRF administration increases colorectal distension-evoked nociceptive responses and in all the cases visceral hypersensitivity can be reversed by CRF1 antagonists. Yet, in human administration of CRF increases colonic motility and hypersensitivity to distension, effects that are exacerbated in patients with IBS (295). Other neuropeptides which have a role in visceral pain sensation and, therefore could be potentially therapeutic targets, include CGRP, somatostatin and cholecystokinin (279).

Over recent years, increasing attention has been placed also toward the adenosine system, which represents a crucial link between the enteric neuromuscular layer and the immune components of the gut. Studies in rodents have shown a significant involvement of adenosine in the control of intestinal secretion, motility and sensation, via activation of $\mathrm{A} 1, \mathrm{~A} 2 \mathrm{~A}, \mathrm{~A} 2 \mathrm{~B}$ or $\mathrm{A} 3$ purinergic receptors, as well as the participation of ATP in the regulation of enteric functions, through the recruitment of $\mathrm{P} 2 \mathrm{X}$ and P2Y receptors (296). Expression of nociceptivespecific P2X3 ATP receptors is up-regulated in colonic nerve fibres of individuals with IBS (297). It is interesting to observe that $\mathrm{P} 2 \mathrm{X} 3$ receptors seems not involved in sensory signalling under physiological conditions whereas they modulate visceral hypersensitivity during acute and in the post-inflammatory phase, although via different mechanisms of sensitization (298). Spinal microglial P2X4 receptors are also activated after visceral injury. The consequent microglia activation evokes inflammatory cytokines release that contribute to central sensitization (297). Furthermore, the activation of neuronal $\mathrm{P} 2 \mathrm{X} 7$ receptor-Pannexin-1 complex resulted as mediators of death of enteric neurons during co- litis (151). Recent evidences suggest a P2X7-dependent-glutamate release in cerebro-cortical nerve terminals of neuropathic animals $(299,300)$, a mechanism that could occur also in the enteric neurons with implication in the sensitization of visceral afferents. Opposite of ATP, the neurotransmitter adenosine seems mediate pain suppression. In fact, the spinally injection of two ectonucleotidases, able to generate adenosine in nociceptive neurons, showed long-lasting adenosine A1 receptor-dependent antinociceptive effects in inflammatory and neuropathic pain models (301).

It has been demonstrated that increasing endogenous adenosine levels through selective adenosine kinase inhibition produces powerful analgesic effects in rodent models of experimental neuropathic pain through the $A 3$ adenosine receptor (A3AR, now known as ADORA3) signalling pathway $(302,303)$. Of particular interest are the highly selective A3AR agonists developed by Tosh et al. (304) which lack the cardiovascular side effects known for other AR agonists, such as A1AR agonists which also provide pain relief (305).

The protective effect of A3AR agonists in chronic pain has been demonstrated to be dependent on GABAergic transmission, but not cannabinoid or opioid receptors, in the spinal cord, and that both peripheral sensory neurons and brain are involved. When peripherally administered A3AR agonists were reported to inhibit pro-inflammatory cytokine expression (306) and to correct the imbalance in dorsal horn cytokines, oxidative pathways, and glutamatergic transmission associated with different pain state (307-309). Recently, it has been reported that the selective stimulation of A3AR inhibits $\mathrm{N}$ type voltage-gated $\mathrm{Ca}^{2+}$ channels (Cav2.2) opening and decreases the electrically evoked excitation of isolated rat dorsal root ganglia (DRG) neurons (310), a mechanism that could explain the anti-hyperalgesic effect of A3AR agonists across models of chronic pain with different aetiologies. The pleiotropic activity of these molecules could represent an important feature in the context of visceral pain 
which usually displays a complex nature with mixed nociceptive, emotional, neuropathic and inflammatory components (as described in the previous paragraphs).

\section{Animal models of visceral pain}

\section{Visceral pain assessment in animals}

Rats and mice are the most commonly used animal models used to assess colonic physiology, pathophysiology, and new therapeutic approaches for visceral pain. In general, there are multiple, well-established methodologies to universally quantify visceral nociception in rats and mice. The most commonly used technique involves recording devices such as electromyographic (EMG) electrodes or strain gauges implanted on the external oblique $a b$ dominal musculature, to quantify the number of reflex abdominal muscle contractions (viscero-motorresponse, VMR) in response to graded colonic balloon distension (CRD) $(311,312)$. Measurement of isobaric distension pressures with a barostat offers numerous strengths, such as an objective assessment of nociceptive reflexes, allowing for assessment of colonic compliance, as well as mimicking the approach used in clinical studies in which sensitivity is assessed in response to rectosigmoid distension. However, there are also weaknesses that must be considered in the data interpretation. For example, the animals may be exposed to stress during the procedure as a result of the novel laboratory environment or may be restrained to reduce movement artifacts during EMG recording. An acclimatization period to the experimental environment has been shown to significantly reduce animal stress and allows for the assessment of visceral sensitivity in a freely moving animal. An additional approach to assess colonic sensitivity is by the visual assessment of the abdominal withdrawal reflex (AWR) in response to CRD $(312,313)$. This technique shows a high sensitivity, however, the AWR is a subjective behavioural measure, requiring larger samples sizes to demonstrate significant differences between treatment groups. An alternative approach to the use of a colonic balloon distension paradigm is to directly stimulate visceral nociceptors through colonic infusion of algesic chemicals, such as capsaicin or mustard oil. Such substances produce spontaneous nocifensive behaviors (perianal licking, abdominal retraction or compression, and hindlimb stretching). A note of caution in the data interpretation is that the inflammatory component of the stimulus suggests that the model may more relevant to inflammatory pain rather than functional visceral pain (314).

\section{Genetic/Spontaneous models of visceral hypersensi- tivity}

Knockout models provide the opportunity to investigate the role of a specific gene in the regulation of colonic sensitivity.

For example, there is a significant decrease in colonic sensitivity to CRD in CRF-1 receptor knockout mice, suggesting the importance of CRF in colonic sensitivity (315). Further studies in knockout mice have demonstrated the importance of other signalling molecules and transporters in the regulation of colonic sensitivity, including BDNF, GC-C, 5HT, and IL-10, human excitatory amino acid transporter 2 (EAAT2), and the serotonin reuptake transporter (SERT) (314). Anyway, nterpretation of data in genetic models is complicated and represents a significant challenge. For example, gene deletion may affect the overall health of the animal along with endogenous compensatory and/or redundant mechanisms that mask the true effect of the loss of the gene.

Multiple studies have confirmed that the WistarKyoto (WKY) rat has a hypersensitive response to colonic distension (316). No single mechanism has been demonstrated to be responsible for the hypersensitive response in WKY rats.

Recent studies have shown that both central and peripheral CRF receptors are differentially expressed and that selective CRF antagonists can inhibit colonic hypersensitivity $(182,183,317,318)$. An issue with the WKY rats is that, the inbred nature of this strain may limit the translational relevance because 
they may only model the pain experienced by a subgroup of patients with functional visceral pain (314).

\section{Early Life Stress models of visceral pain}

Increasing evidence from clinical studies suggests that a history of Early Life Stress (ELS) serves as a risk factor for the development of adult pathologies including but not limited to GI disorders such as IBS, with affected patients being two to four times more likely to report an adverse experience during childhood (319). Although the complex nature of the human ELS experience cannot be completely simulated in animal models, animal models of ELS are important tools to develop our understanding of how adverse neonatal experiences alter brain-gut communication that may lead to the development of abnormal visceral perception. The most well studied model of ELS is maternal separation (MS), which involves removal of pups from mother and nest, most commonly for $3 \mathrm{~h} /$ day on postnatal (PN) day 2-14 (320). The purpose of this paradigm is to mimic childhood neglect and abuse through separation and subsequent alterations in maternal care, including altered licking and grooming behaviors and arched-back nursing (110,320). MS pups exhibit decreased weaning body weight at PND22 compared with controls that are left undisturbed in their home cage on PND2, potentially introducing the effects of malnutrition as a side effect of neglect in this ELS model. In adulthood, there are contradictory results on visceral sensitivity depending on the duration of separation. However, a $3 \mathrm{~h}$ /day separation has been shown to result in visceral hypersensitivity, as evidenced by an increased VMR to CRD in male Long-Evans rats (321). This model is useful to investigate the relationship between ELS and subsequent development of visceral hypersensitivity, in conjunction with hyper-reactivity of the HPA axis, two commonly comorbid symptoms in disorders such as IBS $(27,322)$. The odor-attachment learning (OAL) model of ELS is a classical conditioning model that utilizes predictable or unpredictable odor-shock pairings to mirror an attachment to an abusive caregiver (323). Conditioning occurs from PND8-12 wherein rat pups are experiencing both a sensitive and a hyporesponsive period. These are evolutionary advantages that allow the pups to be more sensitive to maternal odors to find the dam in the cage for care and nursing (324). In adulthood, OAL induces female-specific visceral hypersensitivity in adult Long-Evans rats (325). This model of ELS has far reaching relevance to translational research as it parallels the female predominance found in patients who experience visceral pain (326). A third model of ELS, limited nesting, aims to mirror the neglect and abuse found in areas of poverty or lower socioeconomic standing (327). From PND2 to PND9, all bedding material is removed, and the dam and pups are placed on a wire cage bottom with only a single paper towel for nesting material. This limitation of bedding material causes disruptions in normal maternal care similar to those exhibited by dams during the MS protocol, however, the limited nesting model does not require removal of pups from the dam at any time during the experimental paradigm.

This advantage also eliminates differences in weaning weights seen in the MS model (328). Another model of ELS utilizes neonatal colonic irritation using colonic infusion of mustard oil or repeated CRD in neonates (329). Colonic irritation results in altered neuronal excitability and permeability within the colon, as well as visceral hypersensitivity of adult animals (329-331). This model may be relevant in instances of repeated physical or sexual abuse, and potentially in patients who experience some type of colonic inflammation during childhood (314).

\section{Stress-Induced models of colonic hypersensitivity in adulthood}

As a model of stress targeting only the amygdala, implantation of corticosterone (CORT) micro-pellets on the dorsal surface of the central nucleus of

the amygdala (CeA) were initially shown to increase colonic sensitivity to innocuous distension 
(332). An interesting feature of this model is its relevance to patients with IBS based on imaging studies showing heightened activation of the amygdala in IBS patients in response to colonic distension $(333,334)$. Careful stereotaxic targeting of the $\mathrm{CeA}$ is necessary, since placement of the CORT micropellet in adjacent nuclei does not reproduce the colonic hypersensitivity (335).

Another model of stress is that induced by animal restraints, preventing turning and grooming. A strength of the model is the robust and reproducible increase in colonic sensitivity to distension (336). A stronger model of a psychological stressor-induced colonic hypersensitivity is that represented by the Water Avoidance paradigm, wherein the rat is placed on a dry platform surrounded by water. However, this model may also engage the fear neurocircuitry, which could evoke freezing behaviors in the colonic distension paradigm and affect interpretation of data using this model. With the exception of two studies $(337,338)$, water avoidance stress (WAS) in rats induce colonic hypersensitivity to distension (179). The duration of colonic hypersensitivity to distension, measured through EMG or AWR, was strain dependent with a duration of action of up to $48 \mathrm{~h}$ post-stress. A common issue is that in rat models of stress-related visceral pain the nature of the stressors, including whether they are physical vs. psychological, acute vs. chronic, or predictable vs. unpredictable, can have a profound influence not only on the outcome of the investigation but also on the biological processes involved (314).

\section{Colonic irritation models of hypersensitivity}

Acetic acid has been used to induce colonic hypersensitivity to distension through two different mechanisms. Low-concentration $(\sim 1.0 \%)$ acetic acid produces a transient sensitization of colonic afferents $(339,340)$. Higher concentrations of acetic acid produce a mild damage to the colon, producing inflammation-associated hypersensitivity. To produce a noninflammatory model of colonic hypersensitivity with potential translational relevance to
IBS, Bourdu et al. (341) used repeated butyrate enemas which resulted able to induce colonic hypersensitivity without evidence of inflammation or histological damage. Yet, the colonic installation of a low volume of capsaicin or mustard oil induces pain through direct activation of receptors on afferents as well as establishing an acute inflammation through tissue damage and is typically used to evaluate the analgesic properties of novel therapeutics.

Stereotypic pain behaviors, such as abdominal licking, stretching, retraction, or compressing on the cage floor, are measured after irritant administration (314)

\section{Models of post-infection/inflammatory visceral pain}

These models attempt to mirror the postinflammatory/infective hypersensitivity that develops in some patients. Based on the current understanding of post-inflammatory/infective- (PI-) visceral hypersensitivity (PI-IBS), in an ideal animal model, the animals should not only completely recover from the acute intestinal infection or inflammation but also show intestinal features such as visceral hypersensitivity, motility dysfunction, and changes in permeability or secretion (342).

To model postinfective IBS, bacterial gastroenteritis has been induced in rat and mouse by inoculating certain bacterial strains, as Citrobacter rodentium (343), Campylobacter jejuni $(344,345)$ and Trichinella spiralis (346). Noteworthy, despite their efficacy to cause visceral pain, additional precautions should be exercised when using the post-infective models to protect the experimenters from the pathogens (314).

Regarding postinflammatory IBS, owing to their low cost and rapid onset of disease, chemical models are considered invaluable to the study of various aspects of IBS $(80,347)$. Among the irritants used to induce post-inflammatory IBS there are acetic acid, DSS, and TNBS.

Following recovery from an acute colitis induced by these chemicals, determined by gross morphology, histology, and/or tissue immune activation markers 
(cytokines), these animals develop a hypersensitive response to colonic distension.

The standard protocol for acetic acid-induced postinflammatory colonic hypersensitivity is to administer an enema of $4 \%$ acetic acid, followed by a buffered saline enema, with colonic hypersensitivity lasting 7 days post-enema (348).

Strong evidence for post-inflammatory colonic hypersensitivity following dextran sodium sulfate (DSS) colitis is lacking in recent literature. Acute, chronic and relapsing models of intestinal inflammation can be achieved by modifying the concentration of DSS and the frequency of administration $(349,350)$. Although hypersensitivity to distension was demonstrated at 10 days post-DSS administration (351), colonic sensitivity was similar to control animals at 40 days post-colitis (352). Besides, in rats, colonic hypersensitivity has been observed 14112 days post-TNBS enema. 2,4,6-trinitrobenzenesulfonic acid (TNBS) is a hapten that produces an acute colonic inflammation when administered as an enema in combination with $25-50 \%$ ethanol $(\mathrm{EtOH})$. Ethanol is a prerequisite to break the colonic mucosal barrier to allow penetration of TNBS into the lamina propria where TNBS haptenize the localized colonic and microbial proteins to become immunogenic, thereby triggering the host innate and adaptive immune responses (353). In general, TNBS model is associated with severe and sometimes bloody diarrhoea, weight loss and intestinal wall thickening however symptoms vary depending upon the type of rodent used, as well as the timing, dose and degree of exposure to TNBS used in the study $(353,354)$. The features of IBS, such as visceral hypersensitivity, motility dysfunction and changes in permeability and secretion, have also been identified in the experimental animals after recovery from the initial inflammation induced TNBS $(342,353)$. Moreover, both tegaserod and linaclotide have been shown to inhibit TNBS-induced post-inflammatory colonic hypersensitivity, providing evidence for the translational relevance of the model $(258,355)$. All these evidences made TNBS the most commonly used model of pot-inflammatory IBS. TNBS is considered as a hazardous chemical due to its highly oxidative properties so 2,4-DiNitroBenzene Sulfonic acid (DNBS) is currently regarded as a preferred choice to induce IBS (356). Despite the numerous aspects similar to IBS patients found in the TNBS and DNBS models, the experimental protocols are variegated and poorly defined because of the great variability in the animal's responses to the damage (80). Indeed, the recovery from the colitis does not guarantee the existence for colonic hypersensitivity to balloon distension (357). Optimally, colonic sensitivity to distension should be assessed before testing a therapeutic intervention with only those animals with verified colonic hypersensitivity being used for subsequent testing (314).

\section{Acknowledgements}

The manuscript is an extract from the Introductory statements of Elena Lucarini's PhD thesis entitled "Study of post-inflammatory visceral hypersensitivity mechanisms and innovative treatments: evidence of adenosine $\mathrm{A}^{3}$ receptor agonists efficacy and microbiota relevance in abdominal pain persistence". This research was supported by the Italian Ministry of Instruction, University and Research and by the University of Florence.

\section{Conflict of interests}

The authors declare that they have no conflict of interests.

\section{References}

1. Kennedy R, and Abd-Elsayed A. In: Abd-Elsayed A ed. Pain: A Review Guide. Cham: Springer International Publishing; 2019:1101-3.

2. Aziz Q, Giamberardino MA, Barke A, Korwisi B, Baranowski AP, Wesselmann U, et al. The IASP classification of chronic pain for ICD-11: chronic secondary visceral pain. Pain. 2019;160(1):69-76.

3. Procacci P, Zoppi M, and Maresca M. In: Cervero F, and Morrison JFB eds. Progress in Brain Research. Elsevier; 1986:21-8. 
4. Foley BS. Wall and Melzack's Textbook of Pain, 5th Edition. American Journal of Physical Medicine \& Rehabilitation. 2006;85(7):581.

5. Sikandar S, and Dickenson AH. Visceral pain: the ins and outs, the ups and downs. Curr Opin Support Palliat Care. 2012;6(1):17-26.

6. Longstreth GF, Thompson WG, Chey WD, Houghton LA, Mearin F, and Spiller RC. Functional bowel disorders. Gastroenterology. 2006;130(5):1480-91.

7. Mansfield KE, Sim J, Jordan JL, and Jordan KP. A systematic review and meta-analysis of the prevalence of chronic widespread pain in the general population. Pain. 2016;157(1):55-64.

8. Regueiro M, Greer JB, and Szigethy E. Etiology and Treatment of Pain and Psychosocial Issues in Patients With Inflammatory Bowel Diseases. Gastroenterology. 2017;152(2):430-9.e4.

9. Sperber AD, Dumitrascu D, Fukudo S, Gerson C, Ghoshal UC, Gwee KA, et al. The global prevalence of IBS in adults remains elusive due to the heterogeneity of studies: a Rome Foundation working team literature review. Gut. 2017;66(6):1075-82.

10. Lewis SJ, and Heaton KW. Stool form scale as a useful guide to intestinal transit time. Scand J Gastroenterol. 1997;32(9):920-4.

11. Cervero F, and Laird JM. Understanding the signaling and transmission of visceral nociceptive events. J Neurobiol. 2004;61(1):45-54.

12. El-Salhy M, Ostgaard H, Gundersen D, Hatlebakk JG, and Hausken $\mathrm{T}$. The role of diet in the pathogenesis and management of irritable bowel syndrome (Review). Int J Mol Med. 2012;29(5):723-31.

13. El-Salhy M, Gundersen D, Gilja OH, Hatlebakk JG, and Hausken T. Is irritable bowel syndrome an organic disorder? World J Gastroenterol. 2014;20(2):384-400.

14. Cairns BE, Arendt-Nielsen L, and Sacerdote P. Perspectives in Pain Research 2014: Neuroinflammation and glial cell activation: The cause of transition from acute to chronic pain? Scand J Pain. 2015;6(1):3-6.

15. Coyle DE. Partial peripheral nerve injury leads to activation of astroglia and microglia which parallels the development of allodynic behavior. Glia. 1998;23(1):75-83 .

16. Sweitzer SM, Colburn RW, Rutkowski M, and DeLeo JA. Acute peripheral inflammation induces moderate glial activation and spinal IL-1beta expression that correlates with pain behavior in the rat. Brain Res. 1999;829(1-2):209-21.

17. Larauche M, Mulak A, and Taché Y. Stress and visceral pain: from animal models to clinical therapies. Experimental neurology. 2012;233(1):49-67.

18. Morales-Soto W, and Gulbransen BD. Enteric Glia: A New Player in Abdominal Pain. Cell Mol Gastroenterol Hepatol. 2019;7(2):433-45.

19. Schirbel A, Reichert A, Roll S, Baumgart DC, Büning C, Wittig $\mathrm{B}$, et al. Impact of pain on health-related quality of life in patients with inflammatory bowel disease. World J Gastroenterol. 2010;16(25):3168-77.

20. Srinath AI, Walter C, Newara MC, and Szigethy EM. Pain management in patients with inflammatory bowel disease: insights for the clinician. Therap Adv Gastroenterol. 2012;5(5):339-57

21. Keohane J, O'Mahony C, O'Mahony L, O'Mahony S, Quigley EM, and Shanahan F. Irritable bowel syndrome-type symptoms in patients with inflammatory bowel disease: a real association or reflection of occult inflammation? Am J Gastroenterol. 2010;105(8):1788, 9-94; quiz 95.

22. Minderhoud IM, Oldenburg B, Wismeijer JA, van Berge
Henegouwen GP, and Smout AJ. IBS-like symptoms in patients with inflammatory bowel disease in remission; relationships with quality of life and coping behavior. Dig Dis Sci. 2004;49(3):469-74.

23. Halpin SJ, and Ford AC. Prevalence of symptoms meeting criteria for irritable bowel syndrome in inflammatory bowel disease: systematic review and meta-analysis. Am J Gastroenterol. 2012;107(10):1474-82.

24. Colombel JF, Narula N, and Peyrin-Biroulet L. Management Strategies to Improve Outcomes of Patients With Inflammatory Bowel Diseases. Gastroenterology. 2017;152(2):351-61.e5.

25. Camilleri M, and Boeckxstaens G. Dietary and pharmacological treatment of abdominal pain in IBS. Gut. 2017;66(5):966-74.

26. Whitehead WE, Palsson O, and Jones KR. Systematic review of the comorbidity of irritable bowel syndrome with other disorders: what are the causes and implications? Gastroenterology. 2002;122(4):1140-56.

27. Whitehead WE, Palsson OS, Levy RR, Feld AD, Turner M, and Von Korff M. Comorbidity in irritable bowel syndrome. Am J Gastroenterol. 2007;102(12):2767-76.

28. Spetalen S, Sandvik L, Blomhoff S, and Jacobsen MB. Rectal visceral sensitivity in women with irritable bowel syndrome without psychiatric comorbidity compared with healthy volunteers. Gastroenterol Res Pract. 2009;2009:130684-.

29. Garakani A, Win T, Virk S, Gupta S, Kaplan D, and Masand PS. Comorbidity of irritable bowel syndrome in psychiatric patients: a review. Am J Ther. 2003;10(1):61-7.

30. Frissora CL, and Koch KL. Symptom overlap and comorbidity of irritable bowel syndrome with other conditions. Curr Gastroenterol Rep. 2005;7(4):264-71.

31. Gupta A, and Silman AJ. Psychological stress and fibromyalgia: a review of the evidence suggesting a neuroendocrine link. Arthritis Res Ther. 2004;6(3):98-106.

32. Van Houdenhove B, Egle U, and Luyten P. The role of life stress in fibromyalgia. Curr Rheumatol Rep. 2005;7(5):365-70.

33. Mikocka-Walus AA, Turnbull DA, Andrews JM, Moulding NT, Wilson IG, Harley HA, et al. Psychological problems in gastroenterology outpatients: A South Australian experience. Psychological co-morbidity in IBD, IBS and hepatitis C. Clin Pract Epidemiol Ment Health. 2008;4:15.

34. Park HJ, Jarrett M, Cain K, and Heitkemper M. Psychological distress and GI symptoms are related to severity of bloating in women with irritable bowel syndrome. Res Nurs Health. 2008;31(2):98-107.

35. Moloney RD, O'Mahony SM, Dinan TG, and Cryan JF. Stressinduced visceral pain: toward animal models of irritable-bowel syndrome and associated comorbidities. Frontiers in psychiatry. 2015;6:15-

36. Macer BJ, Prady SL, and Mikocka-Walus A. Antidepressants in Inflammatory Bowel Disease: A Systematic Review. Inflamm Bowel Dis. 2017;23(4):534-50.

37. Handbook of pain assessment. New York, NY, US: The Guilford Press; 1992.

38. Boden SD, Davis DO, Dina TS, Patronas NJ, and Wiesel SW. Abnormal magnetic-resonance scans of the lumbar spine in asymptomatic subjects. A prospective investigation. J Bone Joint Surg Am. 1990;72(3):403-8.

39. Wiesel SW, Feffer HL, and Rothman RH. Industrial low-back pain. A prospective evaluation of a standardized diagnostic and treatment protocol. Spine (Phila Pa 1976). 1984;9(2):199-203.

40. Mujagic Z, Tigchelaar EF, Zhernakova A, Ludwig T, RamiroGarcia J, Baranska A, et al. A novel biomarker panel for irritable bowel syndrome and the application in the general population. 
Scientific reports. 2016;6:26420.

41. Keszthelyi D, Troost FJ, and Masclee AA. Irritable bowel syndrome: methods, mechanisms, and pathophysiology. Methods to assess visceral hypersensitivity in irritable bowel syndrome. Am J Physiol Gastrointest Liver Physiol. 2012;303(2):G141-54.

42. Mayer EA, Aziz Q, Coen S, Kern M, Labus JS, Lane R, et al. Brain imaging approaches to the study of functional GI disorders: a Rome working team report. Neurogastroenterol Motil. 2009;21(6):579-96.

43. Price DD, Robinson ME, and Verne GN. Chronic Abdominal and Visceral Pain. CRC Press; 2006:145-58.

44. Bouin M, Plourde V, Boivin M, Riberdy M, Lupien F,Laganiere $\mathrm{M}$, et al. Rectal distention testing in patients with irritable bowel syndrome: sensitivity, specificity, and predictive values of pain sensory thresholds. Gastroenterology. 2002;122(7):1771-7.

45. Delvaux M. Role of visceral sensitivity in the pathophysiology of irritable bowel syndrome. Gut. 2002;51 Suppl 1:i67-71.

46. Ludidi S, Conchillo JM, Keszthelyi D, Van Avesaat M, Kruimel JW, Jonkers DM, et al. Rectal hypersensitivity as hallmark for irritable bowel syndrome: defining the optimal cutoff. Neurogastroenterol Motil. 2012;24(8):729-33, e345-6.

47. Piche T, Ducrotte P, Sabate JM, Coffin B, Zerbib F, Dapoigny $\mathrm{M}$, et al. Impact of functional bowel symptoms on quality of life and fatigue in quiescent Crohn disease and irritable bowel syndrome. Neurogastroenterol Motil. 2010;22(6):626-e174.

48. Kyloh M, Nicholas S, Zagorodnyuk VP, Brookes SJ, and Spencer NJ. Identification of the visceral pain pathway activated by noxious colorectal distension in mice. Front Neurosci. 2011:5:16.

49. van der Schaar PJ, Lamers CB, and Masclee AA. The role of the barostat in human research and clinical practice. Scand J Gastroenterol Suppl. 1999;230:52-63.

50. Mayer EA, Bradesi S, Chang L, Spiegel BM, Bueller JA, and Naliboff BD. Functional GI disorders: from animal models to drug development. Gut. 2008;57(3):384-404.

51. Posserud I, Stotzer PO, Bjornsson ES, Abrahamsson H, and Simren M. Small intestinal bacterial overgrowth in patients with irritable bowel syndrome. Gut. 2007;56(6):802-8.

52. Mertz H, Naliboff B, Munakata J, Niazi N, and Mayer EA. Altered rectal perception is a biological marker of patients with irritable bowel syndrome. Gastroenterology. 1995;109(1):4052.

53. Accarino AM, Azpiroz F, and Malagelada JR. Symptomatic responses to stimulation of sensory pathways in the jejunum. American Journal of Physiology-Gastrointestinal and Liver Physiology. 1992;263(5):G673-G7.

54. Li Y, Wang Y, Zuo X, Guo Y, Zhang H, Lu X, et al. Visceral perception thresholds after rectal thermal and pressure stimuli in irritable bowel syndrome patients. J Gastroenterol Hepatol. 2004;19(2):187-91.

55. Hammer J, Hammer HF, Eherer AJ, Petritsch W, Holzer P, and Krejs GJ. Intraluminal capsaicin does not affect fluid and electrolyte absorption in the human jejunum but does cause pain. Gut. 1998;43(2):252-5.

56. Fuhrer M, Vogelsang H, and Hammer J. A placebo-controlled trial of an oral capsaicin load in patients with functional dyspepsia. Neurogastroenterol Motil. 2011;23(10):918-e397.

57. Ness TJ, and Gebhart GF. Visceral pain: a review of experimental studies. Pain. 1990;41(2):167-234.

58. Furness JB. The enteric nervous system and neurogastroenterology. Nat Rev Gastroenterol Hepatol. 2012;9(5):286-94.
59. Lakhan SE, and Kirchgessner A. Neuroinflammation in inflammatory bowel disease. J Neuroinflammation. 2010;7:37.

60. Grundy D. Neuroanatomy of visceral nociception: vagal and splanchnic afferent. Gut. 2002;51 Suppl 1(Suppl 1):i2-i5.

61. Sternini C, De Giorgio R, and Furness JB. Calcitonin generelated peptide neurons innervating the canine digestive system. Regul Pept. 1992;42(1-2):15-26.

62. Bellono NW, Bayrer JR, Leitch DB, Castro J, Zhang C, O'Donnell TA, et al. Enterochromaffin Cells Are Gut Chemosensors that Couple to Sensory Neural Pathways. Cell. 2017;170(1):185-98.e16.

63. Sengupta JN,Gebhart GF.Mechanosensitive properties of pelvic nerve afferent fibers innervating the urinary bladder of the rat. $\mathbf{J}$ Neurophysiol. 1994;72(5):2420-30.

64. Giamberardino MA, and Vecchiet L. Pathophysiology of visceral pain. Current Pain and Headache Reports. 1997;1(1):23-33

65. Smith-Edwards KM, Najjar SA, Edwards BS, Howard MJ, Albers KM, and Davis BM. Extrinsic Primary Afferent Neurons Link Visceral Pain to Colon Motility Through a Spinal Reflex in Mice. Gastroenterology. 2019;157(2):522-36.e2.

66. Cervero F. Sensory innervation of the viscera: peripheral basis of visceral pain. Physiol Rev. 1994;74(1):95-138.

67. Berthoud HR, and Neuhuber WL. Functional and chemical anatomy of the afferent vagal system. Auton Neurosci. 2000;85(1-3):1-17.

68. Sengupta JN, Saha JK, and Goyal RK. Stimulus-response function studies of esophageal mechanosensitive nociceptors in sympathetic afferents of opossum. J Neurophysiol. 1990;64(3):796-812.

69. Gebhart GF. Visceral pain-peripheral sensitisation. Gut. 2000;47 Suppl 4:iv54-5; discussion iv8.

70. Cameron DM, Brennan TJ, and Gebhart GF. Hind paw incision in the rat produces long-lasting colon hypersensitivity. J Pain. 2008;9(3):246-53.

71. Joshi SK, and Gebhart GF. Visceral pain. Curr Rev Pain. 2000;4(6):499-506.

72. Hunt SP, and Mantyh PW. The molecular dynamics of pain control. Nat Rev Neurosci. 2001;2(2):83-91.

73. Bester H, Menendez L, Besson JM, and Bernard JF. Spino (trigemino) parabrachiohypothalamic pathway: electrophysiological evidence for an involvement in pain processes. J Neurophysiol. 1995;73(2):568-85.

74. Morton DL, Sandhu JS, and Jones AK. Brain imaging of pain: state of the art. J Pain Res. 2016;9:613-24.

75. Wilder-Smith $\mathrm{CH}$. The balancing act: endogenous modulation of pain in functional gastrointestinal disorders. Gut. 2011;60(11):1589-99.

76. Bushnell MC, Ceko M, and Low LA. Cognitive and emotional control of pain and its disruption in chronic pain. Nat Rev Neurosci. 2013;14(7):502-11.

77. Navratilova E, and Porreca F. Reward and motivation in pain and pain relief. Nat Neurosci. 2014;17(10):1304-12.

78. Heinricher MM, Tavares I, Leith JL, and Lumb BM. Descending control of nociception: Specificity, recruitment and plasticity. Brain Res Rev. 2009;60(1):214-25.

79. Denk F, McMahon SB, and Tracey I. Pain vulnerability: a neurobiological perspective. Nat Neurosci. 2014;17(2):192200.

80. Giamberardino MA. Visceral pain: clinical, pathophysiological and therapeutic aspects. Oxford University Press; 2009.

81. Cervero F, and Laird JM. Visceral pain. Lancet. 1999;353(9170):2145-8. 
82. Neugebauer V, Li W, Bird GC, and Han JS. The amygdala and persistent pain. Neuroscientist. 2004;10(3):221-34.

83. Elsenbruch S, Rosenberger C, Enck P, Forsting M, Schedlowski $\mathrm{M}$, and Gizewski ER. Affective disturbances modulate the neural processing of visceral pain stimuli in irritable bowel syndrome: an fMRI study. Gut. 2010;59(4):489-95.

84. Mayer EA. Emerging disease model for functional gastrointestinal disorders. Am J Med. 1999;107(5a):12s-9s.

85. Cryan JF, O'Riordan KJ, Cowan CSM, Sandhu KV, Bastiaanssen TFS, Boehme M, et al. The Microbiota-Gut-Brain Axis. Physiol Rev. 2019;99(4):1877-2013.

86. Spiller R, and Major G. IBS and IBD - separate entities or on a spectrum? Nat Rev Gastroenterol Hepatol. 2016;13(10):613-21.

87. Sinagra E, Romano C, and Cottone M. Psychopharmacological treatment and psychological interventions in irritable bowel syndrome. Gastroenterol Res Pract. 2012;2012:486067-.

88. Vivinus-Nebot M, Frin-Mathy G, Bzioueche H, Dainese R, Bernard G, Anty R, et al. Functional bowel symptoms in quiescent inflammatory bowel diseases: role of epithelial barrier disruption and low-grade inflammation. Gut. 2014;63(5):74452.

89. Khor B, Gardet A, and Xavier RJ. Genetics and pathogenesis of inflammatory bowel disease. Nature. 2011;474(7351):307-17.

90. Buning C, Geissler N, Prager M, Sturm A, Baumgart DC, Buttner $\mathrm{J}$, et al. Increased small intestinal permeability in ulcerative colitis: rather genetic than environmental and a risk factor for extensive disease? Inflamm Bowel Dis. 2012;18(10):1932-9.

91. Vanuytsel T, van Wanrooy S, Vanheel H, Vanormelingen C, Verschueren S, Houben E, et al. Psychological stress and corticotropin-releasing hormone increase intestinal permeability in humans by a mast cell-dependent mechanism. Gut. 2014;63(8):1293-9.

92. Keita AV, Carlsson AH, Cigehn M, Ericson AC, McKay DM, and Soderholm JD. Vasoactive intestinal polypeptide regulates barrier function via mast cells in human intestinal follicleassociated epithelium and during stress in rats. Neurogastroenterol Motil. 2013;25(6):e406-17.

93. Larauche $\mathrm{M}$, Gourcerol $\mathrm{G}$, Wang L, Pambukchian $\mathrm{K}$, Brunnhuber S, Adelson DW, et al. Cortagine, a CRF1 agonist, induces stresslike alterations of colonic function and visceral hypersensitivity in rodents primarily through peripheral pathways. American journal of physiology Gastrointestinal and liver physiology. 2009;297(1):G215-27.

94. Mawe GM, and Hoffman JM. Serotonin signalling in the gut-functions, dysfunctions and therapeutic targets. Nat Rev Gastroenterol Hepatol. 2013;10(8):473-86.

95. Cremon C, Carini G, Wang B, Vasina V, Cogliandro RF, De Giorgio R, et al. Intestinal serotonin release, sensory neuron activation, and abdominal pain in irritable bowel syndrome. Am J Gastroenterol. 2011;106(7):1290-8.

96. Dunlop SP, Jenkins D, Neal KR, and Spiller RC. Relative importance of enterochromaffin cell hyperplasia, anxiety, and depression in postinfectious IBS. Gastroenterology. 2003;125(6):1651-9.

97. Andresen V, Montori VM, Keller J, West CP, Layer P, and Camilleri M. Effects of 5-hydroxytryptamine (serotonin) type 3 antagonists on symptom relief and constipation in nonconstipated irritable bowel syndrome: a systematic review and meta-analysis of randomized controlled trials. Clinical gastroenterology and hepatology : the official clinical practice journal of the American Gastroenterological Association. 2008;6(5):545-55.
98. Garsed K, Chernova J, Hastings M, Lam C, Marciani L, Singh $\mathrm{G}$, et al. A randomised trial of ondansetron for the treatment of irritable bowel syndrome with diarrhoea. Gut. 2014;63(10):1617-25.

99. Dunlop SP, Coleman NS, Blackshaw E, Perkins AC, Singh G, Marsden CA, et al. Abnormalities of 5-hydroxytryptamine metabolism in irritable bowel syndrome. Clin Gastroenterol Hepatol. 2005;3(4):349-57.

100. Atkinson W, Lockhart S, Whorwell PJ, Keevil B, and Houghton LA. Altered 5-hydroxytryptamine signaling in patients with constipation- and diarrhea-predominant irritable bowel syndrome. Gastroenterology. 2006;130(1):34-43.

101. Massironi S, Zilli A, Cavalcoli F, Conte D, and Peracchi M. Chromogranin A and other enteroendocrine markers in inflammatory bowel disease. Neuropeptides. 2016;58:127-34.

102. Magro F, Vieira-Coelho MA, Fraga S, Serrao MP, Veloso FT, Ribeiro T, et al. Impaired synthesis or cellular storage of norepinephrine, dopamine, and 5-hydroxytryptamine in human inflammatory bowel disease. Dig Dis Sci. 2002;47(1):216-24.

103. Agus A, Planchais J, and Sokol H. Gut Microbiota Regulation of Tryptophan Metabolism in Health and Disease. Cell Host Microbe. 2018;23(6):716-24.

104. O'Mahony SM, Clarke G, Borre YE, Dinan TG, and Cryan JF. Serotonin, tryptophan metabolism and the brain-gutmicrobiome axis. Behav Brain Res. 2015;277:32-48.

105. Kennedy PJ, Cryan JF, Dinan TG, and Clarke G. Kynurenine pathway metabolism and the microbiota-gut-brain axis. Neuropharmacology. 2017;112(Pt B):399-412.

106. Sjogren K, Engdahl C, Henning P, Lerner UH, Tremaroli V, Lagerquist MK, et al. The gut microbiota regulates bone mass in mice. J Bone Miner Res. 2012;27(6):1357-67.

107. Thabane M, and Marshall JK. Post-infectious irritable bowel syndrome. World J Gastroenterol. 2009;15(29):3591-6.

108. Perez-Cobas AE, Gosalbes MJ, Friedrichs A, Knecht H, Artacho A, Eismann K, et al. Gut microbiota disturbance during antibiotic therapy: a multi-omic approach. Gut. 2013;62(11):1591-601.

109. Goldenberg JZ, Lytvyn L, Steurich J, Parkin P, Mahant S, and Johnston BC. Probiotics for the prevention of pediatric antibiotic-associated diarrhea. Cochrane Database Syst Rev. 2015(12):Cd004827.

110. O'Mahony SM, Marchesi JR, Scully P, Codling C, Ceolho AM, Quigley EM, et al. Early life stress alters behavior, immunity, and microbiota in rats: implications for irritable bowel syndrome and psychiatric illnesses. Biol Psychiatry. 2009;65(3):263-7.

111. Maxwell PR, Rink E, Kumar D, and Mendall MA. Antibiotics increase functional abdominal symptoms. Am J Gastroenterol. 2002;97(1):104-8.

112. Vich Vila A, Imhann F, Collij V, Jankipersadsing SA, Gurry T, Mujagic Z, et al. Gut microbiota composition and functional changes in inflammatory bowel disease and irritable bowel syndrome. Sci Transl Med. 2018;10(472).

113. Muccioli GG, Naslain D, Backhed F, Reigstad CS, Lambert DM, Delzenne NM, et al. The endocannabinoid system links gut microbiota to adipogenesis. Mol Syst Biol. 2010;6:392.

114. Boue J, Basso L, Cenac N, Blanpied C, Rolli-Derkinderen M, Neunlist M, et al. Endogenous regulation of visceral pain via production of opioids by colitogenic CD4(+) $\mathrm{T}$ cells in mice. Gastroenterology. 2014;146(1):166-75.

115. Oleskin AV, and Shenderov BA. Neuromodulatory effects and targets of the SCFAs and gasotransmitters produced by the human symbiotic microbiota. Microb Ecol Health Dis. 2016;27:30971. 
116. Mann ER, Bernardo D, Ng SC, Rigby RJ, Al-Hassi HO, Landy $\mathrm{J}$, et al. Human gut dendritic cells drive aberrant gut-specific tcell responses in ulcerative colitis, characterized by increased IL-4 production and loss of IL-22 and IFNgamma. Inflamm Bowel Dis. 2014;20(12):2299-307.

117. Reboldi A, Arnon TI, Rodda LB, Atakilit A, Sheppard D, and Cyster JG. IgA production requires B cell interaction with subepithelial dendritic cells in Peyer's patches. Science. 2016;352(6287):aaf4822.

118. Vitale S, Picascia S, and Gianfrani C. The cross-talk between enterocytes and intraepithelial lymphocytes. Mol Cell Pediatr. 2016;3(1):20.

119. Spiller RC, Jenkins D, Thornley JP, Hebden JM, Wright T, Skinner M, et al. Increased rectal mucosal enteroendocrine cells, T lymphocytes, and increased gut permeability following acute Campylobacter enteritis and in post-dysenteric irritable bowel syndrome. Gut. 2000;47(6):804-11.

120. Gwee KA, Collins SM, Read NW, Rajnakova A, Deng Y, Graham JC, et al. Increased rectal mucosal expression of interleukin 1 beta in recently acquired post-infectious irritable bowel syndrome. Gut. 2003;52(4):523-6.

121. Wang LH, Fang XC, and Pan GZ. Bacillary dysentery as a causative factor of irritable bowel syndrome and its pathogenesis. Gut. 2004;53(8):1096-101.

122. White FA, Bhangoo SK, and Miller RJ. Chemokines: integrators of pain and inflammation. Nat Rev Drug Discov. 2005;4(10):834-44

123. Cook AD, Christensen AD, Tewari D, McMahon SB, and Hamilton JA. Immune Cytokines and Their Receptors in Inflammatory Pain. Trends Immunol. 2018;39(3):240-55.

124. Lu Y, Xu HM, Han Y, and Zhang YL. Analgesic effect of resveratrol on colitis-induced visceral pain via inhibition of TRAF6/NF-kappaB signaling pathway in the spinal cord. Brain Res. 2019;1724:146464.

125. Milligan E, Zapata V, Schoeniger D, Chacur M, Green P, Poole $S$, et al. An initial investigation of spinal mechanisms underlying pain enhancement induced by fractalkine, a neuronally released chemokine. Eur $\mathrm{J}$ Neurosci. 2005;22(11):2775-82.

126. Krukowski K, Eijkelkamp N, Laumet G, Hack CE, Li Y, Dougherty PM, et al. CD8+ T Cells and Endogenous IL-10 Are Required for Resolution of Chemotherapy-Induced Neuropathic Pain. J Neurosci. 2016;36(43):11074-83.

127. Shen KF, Zhu HQ, Wei XH, Wang J, Li YY, Pang RP, et al. Interleukin-10 down-regulates voltage gated sodium channels in rat dorsal root ganglion neurons. Exp Neurol. 2013;247:466-75.

128. Liebregts T, Adam B, Bredack C, Roth A, Heinzel S, Lester S, et al. Immune activation in patients with irritable bowel syndrome. Gastroenterology. 2007;132(3):913-20.

129. Vara EJ, Brokstad KA, Hausken T, and Lied GA. Altered levels of cytokines in patients with irritable bowel syndrome are not correlated with fatigue. Int J Gen Med. 2018;11:285-91.

130. Salameh E, Meleine M, Gourcerol G, do Rego JC, do Rego JL, Legrand R, et al. Chronic colitis-induced visceral pain is associated with increased anxiety during quiescent phase. Am J Physiol Gastrointest Liver Physiol. 2019;316(6):G692-g700.

131. Diogenes A, Ferraz CC, Akopian AN, Henry MA, and Hargreaves KM. LPS sensitizes TRPV1 via activation of TLR4 in trigeminal sensory neurons. J Dent Res. 2011;90(6):759-64.

132. Nozu T, Miyagishi S, Nozu R, Takakusaki K, and Okumura T. Lipopolysaccharide induces visceral hypersensitivity: role of interleukin-1, interleukin-6, and peripheral corticotropin- releasing factor in rats. J Gastroenterol. 2017;52(1):72-80.

133. Tramullas M, Finger BC, Dinan TG, and Cryan JF. Obesity Takes Its Toll on Visceral Pain: High-Fat Diet Induces TollLike Receptor 4-Dependent Visceral Hypersensitivity. PloS one. 2016;11(5):e0155367-e.

134. Cremon C, Gargano L, Morselli-Labate AM, Santini D, Cogliandro RF, De Giorgio R, et al. Mucosal immune activation in irritable bowel syndrome: gender-dependence and association with digestive symptoms. Am J Gastroenterol. 2009;104(2):392-400.

135. Barbara G, Stanghellini V, De Giorgio R, Cremon C, Cottrell GS, Santini D, et al. Activated mast cells in proximity to colonic nerves correlate with abdominal pain in irritable bowel syndrome. Gastroenterology. 2004;126(3):693-702.

136. Baral P, Umans BD, Li L, Wallrapp A, Bist M, Kirschbaum T, et al. Nociceptor sensory neurons suppress neutrophil and gammadelta $\mathrm{T}$ cell responses in bacterial lung infections and lethal pneumonia. Nat Med. 2018;24(4):417-26.

137. Arizono N, Matsuda S, Hattori T, Kojima Y, Maeda T, and Galli SJ. Anatomical variation in mast cell nerve associations in the rat small intestine, heart, lung, and skin. Similarities of distances between neural processes and mast cells, eosinophils, or plasma cells in the jejunal lamina propria. Lab Invest. 1990;62(5):62634.

138. Alving K, Sundström C, Matran R, Panula P, Hökfelt T, and Lundberg JM. Association between histamine-containing mast cells and sensory nerves in the skin and airways of control and capsaicin-treated pigs. Cell and Tissue Research. 1991;264(3):529-38.

139. Riol-Blanco L, Ordovas-Montanes J, Perro M, Naval E, Thiriot A, Alvarez D, et al. Nociceptive sensory neurons drive interleukin-23-mediated psoriasiform skin inflammation. Nature. 2014;510(7503):157-61.

140. Kashem SW, Riedl MS, Yao C, Honda CN, Vulchanova L, and Kaplan DH. Nociceptive Sensory Fibers Drive Interleukin-23 Production from CD301b+ Dermal Dendritic Cells and Drive Protective Cutaneous Immunity. Immunity. 2015;43(3):515-26.

141. Braak B, Klooker TK, Wouters MM, Welting O, van der Loos $\mathrm{CM}$, Stanisor OI, et al. Mucosal immune cell numbers and visceral sensitivity in patients with irritable bowel syndrome: is there any relationship? Am J Gastroenterol. 2012;107(5):71526.

142. Bennet SM, Polster A, Tornblom H, Isaksson S, Capronnier S, Tessier A, et al. Global Cytokine Profiles and Association With Clinical Characteristics in Patients With Irritable Bowel Syndrome. Am J Gastroenterol. 2016;111(8):1165-76.

143. Chang L, Adeyemo M, Karagiannides I, Videlock EJ, Bowe C, Shih W, et al. Serum and colonic mucosal immune markers in irritable bowel syndrome. Am J Gastroenterol. 2012;107(2):262-72.

144. Simpson J, Sundler F, Humes DJ, Jenkins D, Wakelin D, Scholefield $\mathrm{JH}$, et al. Prolonged elevation of galanin and tachykinin expression in mucosal and myenteric enteric nerves in trinitrobenzene sulphonic acid colitis. Neurogastroenterol Motil. 2008;20(4):392-406.

145. Liebregts T, Adam B, Bertel A, Jones S, Schulze J, Enders C, et al. Effect of E. coli Nissle 1917 on post-inflammatory visceral sensory function in a rat model. Neurogastroenterology \& Motility. 2005;17(3):410-4.

146. Mawe GM. Colitis-induced neuroplasticity disrupts motility in the inflamed and post-inflamed colon. The Journal of Clinical Investigation. 2015;125(3):949-55. 
147. Brierley SM, and Linden DR.Neuroplasticity and dysfunction after gastrointestinal inflammation.Nat Rev Gastroenterol Hepa tol 2014;11(10):611-27.

148. Grubišić V, and Gulbransen BD. Enteric glia: the most alimentary of all glia. The Journal of Physiology. 2017;595(2):557-70.

149. Sharkey KA. Emerging roles for enteric glia in gastrointestinal disorders. J Clin Invest. 2015;125(3):918-25.

150. Wang P, Du C, Chen F-X, Li C-Q, Yu Y-B, Han T, et al. BDNF contributes to IBS-like colonic hypersensitivity via activating the enteroglia-nerve unit. Scientific Reports. 2016;6(1):20320.

151. Gulbransen BD, and Sharkey KA. Novel functional roles for enteric glia in the gastrointestinal tract. Nat Rev Gastroenterol Hepatol. 2012;9(11):625-32.

152. Delvalle NM, Dharshika C, Morales-Soto W, Fried DE, Gaudette L, and Gulbransen BD. Communication Between Enteric Neurons, Glia, and Nociceptors Underlies the Effects of Tachykinins on Neuroinflammation. Cell Mol Gastroenterol Hepatol. 2018;6(3):321-44.

153. Ippolito C, Segnani C, Errede M, Virgintino D, Colucci R, Fornai M, et al. An integrated assessment of histopathological changes of the enteric neuromuscular compartment in experimental colitis. J Cell Mol Med. 2015;19(2):485-500.

154. Huang TY, Belzer V, and Hanani M. Gap junctions in dorsal root ganglia: possible contribution to visceral pain. Eur J Pain. 2010;14(1):49.e1-11.

155. Hanani M, Caspi A, and Belzer V. Peripheral inflammation augments gap junction-mediated coupling among satellite glial cells in mouse sympathetic ganglia. Neuron Glia Biol. 2010;6(1):85-9.

156. Dodds RM, Syddall HE, Cooper R, Kuh D, Cooper C, and Sayer AA. Global variation in grip strength: a systematic review and meta-analysis of normative data. Age Ageing. 2016;45(2):20916.

157. Ren K, and Dubner R. Activity-triggered tetrapartite neuronglial interactions following peripheral injury. Curr Opin Pharmacol. 2016;26:16-25.

158. Maier SF, and Watkins LR. Cytokines for psychologists: implications of bidirectional immune-to-brain communication for understanding behavior, mood, and cognition. Psychol Rev. 1998;105(1):83-107.

159. Ji RR, Berta T, and Nedergaard M. Glia and pain: is chronic pain a gliopathy? Pain. 2013;154 Suppl 1:S10-28.

160. Zhang X, Zeng L, Yu T, Xu Y, Pu S, Du D, et al. Positive Feedback Loop of Autocrine BDNF from Microglia Causes Prolonged Microglia Activation. Cellular Physiology and Biochemistry. 2014;34(3):715-23.

161. Anderson CM, Bergher JP, and Swanson RA. ATP-induced ATP release from astrocytes. J Neurochem. 2004;88(1):246-56.

162. Shiga $\mathrm{H}$, Tojima $\mathrm{T}$, and Ito $\mathrm{E}$. $\mathrm{Ca} 2+$ signaling regulated by an ATP-dependent autocrine mechanism in astrocytes. Neuroreport. 2001;12(12):2619-22.

163. Beggs S, Currie G, Salter MW, Fitzgerald M, and Walker SM. Priming of adult pain responses by neonatal pain experience: maintenance by central neuroimmune activity. Brain : a journal of neurology. 2012;135(Pt 2):404-17.

164. Schwaller F, Beggs S, and Walker SM. Targeting p38 Mitogenactivated Protein Kinase to Reduce the Impact of Neonatal Microglial Priming on Incision-induced Hyperalgesia in the Adult Rat. Anesthesiology. 2015;122(6):1377-90.

165. Grace PM, Hutchinson MR, Maier SF, and Watkins LR. Pathological pain and the neuroimmune interface. Nat Rev Immunol. 2014;14(4):217-31.
166. Milligan ED, and Watkins LR. Pathological and protective roles of glia in chronic pain. Nat Rev Neurosci. 2009;10(1):23-36.

167. Liu PY, Lu CL, Wang CC, Lee IH, Hsieh JC, Chen CC, et al. Spinal microglia initiate and maintain hyperalgesia in a rat model of chronic pancreatitis. Gastroenterology. 2012;142(1):165-73.e2.

168. Song DD, Li Y, Tang D, Huang LY, and Yuan YZ. Neuron-glial communication mediated by TNF-alpha and glial activation in dorsal root ganglia in visceral inflammatory hypersensitivity. Am J Physiol Gastrointest Liver Physiol. 2014;306(9):G788-95.

169. Kannampalli P, Pochiraju S, Bruckert M, Shaker R, Banerjee B, and Sengupta JN. Analgesic effect of minocycline in rat model of inflammation-induced visceral pain. Eur $\mathrm{J}$ Pharmacol. 2014;727:87-98.

170. Ji R-R, Donnelly CR, and Nedergaard M. Astrocytes in chronic pain and itch. Nat Rev Neurosci. 2019;20(11):667-85.

171. Li T, Chen X, Zhang C, Zhang Y, and Yao W. An update on reactive astrocytes in chronic pain. Journal of Neuroinflammation. 2019;16(1):140.

172. Lampe A, Doering S, Rumpold G, Solder E, Krismer M, Kantner-Rumplmair W, et al. Chronic pain syndromes and their relation to childhood abuse and stressful life events. J Psychosom Res. 2003;54(4):361-7.

173. Racine M, Tousignant-Laflamme Y, Kloda LA, Dion D, Dupuis $\mathrm{G}$, and Choiniere M. A systematic literature review of 10 years of research on sex/gender and pain perception - part 2: do biopsychosocial factors alter pain sensitivity differently in women and men? Pain. 2012;153(3):619-35.

174. Greenwood-Van Meerveld B, and Johnson AC. Stress-Induced Chronic Visceral Pain of Gastrointestinal Origin. Front Syst Neurosci. 2017;11:86.

175. Herman JP, and Cullinan WE. Neurocircuitry of stress: central control of the hypothalamo-pituitary-adrenocortical axis. Trends Neurosci. 1997;20(2):78-84.

176. Schulkin J, Gold PW, and McEwen BS. Induction of corticotropin-releasing hormone gene expression by glucocorticoids: implication for understanding the states of fear and anxiety and allostatic load. Psychoneuroendocrinology. 1998;23(3):219-43.

177. Reul JM, and de Kloet ER. Two receptor systems for corticosterone in rat brain: microdistribution and differential occupation. Endocrinology. 1985;117(6):2505-11.

178. Johnson AC, Tran L, and Greenwood-Van Meerveld B. Knockdown of corticotropin-releasing factor in the central amygdala reverses persistent viscerosomatic hyperalgesia. Transl Psychiatry. 2015;5:e517.

179. Myers B, and Greenwood-Van Meerveld B. Differential involvement of amygdala corticosteroid receptors in visceral hyperalgesia following acute or repeated stress. Am J Physiol Gastrointest Liver Physiol. 2012;302(2):G260-6.

180. Drossman DA, Chang L, Bellamy N, Gallo-Torres HE, Lembo A, Mearin F, et al. Severity in irritable bowel syndrome: a Rome Foundation Working Team report. Am J Gastroenterol. 2011;106(10):1749-59; quiz 60.

181. Hooten WM. Chronic Pain and Mental Health Disorders: Shared Neural Mechanisms, Epidemiology, and Treatment. Mayo Clin Proc. 2016;91(7):955-70.

182. Bravo JA, Dinan TG, and Cryan JF. Alterations in the central CRF system of two different rat models of comorbid depression and functional gastrointestinal disorders. Int $\mathbf{J}$ Neuropsychopharmacol. 2011;14(5):666-83.

183. Johnson AC, Tran L, Schulkin J, and Greenwood-Van Meerveld B. Importance of stress receptor-mediated mechanisms in the 
amygdala on visceral pain perception in an intrinsically anxious rat. Neurogastroenterol Motil. 2012;24(5):479-86, e219.

184. Greenwood-Van Meerveld B, Johnson AC, Cochrane S, Schulkin J, and Myers DA. Corticotropin-releasing factor 1 receptor-mediated mechanisms inhibit colonic hypersensitivity in rats. Neurogastroenterol Motil. 2005;17(3):415-22.

185. Czogalla B, Schmitteckert S, Houghton LA, Sayuk GS, Camilleri M, Olivo-Diaz A, et al. A meta-analysis of immunogenetic Case-Control Association Studies in irritable bowel syndrome. Neurogastroenterol Motil. 2015;27(5):717-27.

186. Swan C,Duroudier NP,Campbell E, Zaitoun A, Hastings M, Dukes GE,et al.Identifying and testing candidate genetic polymorphisms in the irritable bowel syndrome(IBS):association with TNFSF15 and TNFalpha.Gut 2013;62(7):985-94.

187. Zucchelli M, Camilleri M, Andreasson AN, Bresso F, Dlugosz A, Halfvarson J, et al. Association of TNFSF15 polymorphism with irritable bowel syndrome. Gut. 2011;60(12):1671-7.

188. Liu JZ, van Sommeren S, Huang H, Ng SC, Alberts R, Takahashi A, et al. Association analyses identify 38 susceptibility loci for inflammatory bowel disease and highlight shared genetic risk across populations. Nat Genet. 2015;47(9):979-86.

189. Burisch J, and Munkholm P. The epidemiology of inflammatory bowel disease. Scand J Gastroenterol. 2015;50(8):942-51.

190. Hungin AP, Whorwell PJ, Tack J, and Mearin F. The prevalence, patterns and impact of irritable bowel syndrome: an international survey of 40,000 subjects. Aliment Pharmacol Ther. 2003;17(5):643-50.

191. Gebhart GF, and Bielefeldt K. Physiology of Visceral Pain. Compr Physiol. 2016;6(4):1609-33.

192. Farre R, and Tack J. Food and symptom generation in functional gastrointestinal disorders: physiological aspects. Am J Gastroenterol. 2013;108(5):698-706.

193. Bohn L, Storsrud S, Tornblom H, Bengtsson U, and Simren M. Self-reported food-related gastrointestinal symptoms in IBS are common and associated with more severe symptoms and reduced quality of life. Am J Gastroenterol. 2013;108(5):63441.

194. Suares NC, and Ford AC. Prevalence of, and risk factors for, chronic idiopathic constipation in the community: systematic review and meta-analysis. Am J Gastroenterol. 2011;106(9):1582-91; quiz 1, 92.

195. Gibson PR, Varney J, Malakar S, and Muir JG. Food components and irritable bowel syndrome. Gastroenterology. 2015;148(6):1158-74.e4.

196. Staudacher HM, and Whelan K. Altered gastrointestinal microbiota in irritable bowel syndrome and its modification by diet: probiotics, prebiotics and the low FODMAP diet. Proc Nutr Soc. 2016;75(3):306-18.

197. McIntosh K, Reed DE, Schneider T, Dang F, Keshteli AH, De Palma G, et al. FODMAPs alter symptoms and the metabolome of patients with IBS: a randomised controlled trial. Gut. 2017;66(7):1241-51.

198. Bohn L, Storsrud S, Liljebo T, Collin L, Lindfors P, Tornblom $\mathrm{H}$, et al. Diet low in FODMAPs reduces symptoms of irritable bowel syndrome as well as traditional dietary advice: a randomized controlled trial. Gastroenterology. 2015;149(6):1399-407.e2.

199. Marsh A, Eslick EM, and Eslick GD. Does a diet low in FODMAPs reduce symptoms associated with functional gastrointestinal disorders? A comprehensive systematic review and meta-analysis. Eur J Nutr. 2016;55(3):897-906.

200. Eswaran SL, Chey WD, Han-Markey T, Ball S, and Jackson K. A Randomized Controlled Trial Comparing the Low FODMAP
Diet vs. Modified NICE Guidelines in US Adults with IBS-D. Am J Gastroenterol. 2016;111(12):1824-32.

201. Halmos EP, Christophersen CT, Bird AR, Shepherd SJ, Gibson PR, and Muir JG. Diets that differ in their FODMAP content alter the colonic luminal microenvironment. Gut. 2015;64(1):93-100.

202. Molina-Infante J, Serra J, Fernandez-Banares F, Mearin F. The low-FODMAP diet for irritable bowel syndrome: Lights and shadows. Gastroenterol Hepatol. 2016;39(2):55-65.

203. Biesiekierski JR, Peters SL, Newnham ED, Rosella O, Muir JG, Gibson PR.No effects of gluten in patients with self-reported non-celiac gluten sensitivity after dietary reduction of fermentable, poorly absorbed,short-chain carbohydrates. Gastroenterology. 2013;145(2):320-8.e1-3.

204. Vazquez-Roque MI, Camilleri M, Smyrk T, Murray JA, Marietta E, O'Neill J, et al. A controlled trial of gluten-free diet in patients with irritable bowel syndrome-diarrhea: effects on bowel frequency and intestinal function. Gastroenterology. 2013;144(5):903-11.e3.

205. Dionne J, Ford AC, Yuan Y, Chey WD, Lacy BE, Saito YA, et al. A Systematic Review and Meta-Analysis Evaluating the Efficacy of a Gluten-Free Diet and a Low FODMAPs Diet in Treating Symptoms of Irritable Bowel Syndrome. Am J Gastroenterol. 2018;113(9):1290-300.

206. Sanchez B, Delgado S, Blanco-Miguez A, Lourenco A, Gueimonde M, and Margolles A. Probiotics, gut microbiota, and their influence on host health and disease. Mol Nutr Food Res. 2017;61(1).

207. Sarkar A, Lehto SM, Harty S, Dinan TG, Cryan JF, and Burnet PWJ. Psychobiotics and the Manipulation of Bacteria-GutBrain Signals. Trends Neurosci. 2016;39(11):763-81.

208. Fadgyas-Stanculete M, Buga AM, Popa-Wagner A, and Dumitrascu DL. The relationship between irritable bowel syndrome and psychiatric disorders: from molecular changes to clinical manifestations. J Mol Psychiatry. 2014;2(1):4.

209. Gibson GR, Hutkins R, Sanders ME, Prescott SL, Reimer RA, Salminen SJ, et al. Expert consensus document: The International Scientific Association for Probiotics and Prebiotics (ISAPP) consensus statement on the definition and scope of prebiotics. Nat Rev Gastroenterol Hepatol. 2017;14(8):491-502.

210. Slavin J. Fiber and prebiotics: mechanisms and health benefits. Nutrients. 2013;5(4):1417-35

211. Wang Q, Sheng X, Shi A, Hu H, Yang Y, Liu L, et al. betaGlucans: Relationships between Modification, Conformation and Functional Activities. Molecules. 2017;22(2).

212. Russo P, Lopez P, Capozzi V, de Palencia PF, Duenas MT, Spano G, et al. Beta-glucans improve growth, viability and colonization of probiotic microorganisms. Int $\mathrm{J}$ Mol Sci. 2012;13(5):6026-39.

213. Belorkar SA, and Gupta AK. Oligosaccharides: a boon from nature's desk. AMB Express. 2016;6(1):82.

214. Pandey P, Ramegowda V, and Senthil-Kumar M. Shared and unique responses of plants to multiple individual stresses and stress combinations: physiological and molecular mechanisms. Front Plant Sci. 2015;6:723-.

215. Markowiak P, and Slizewska K. Effects of Probiotics, Prebiotics, and Synbiotics on Human Health. Nutrients. 2017;9(9).

216. Moloney RD, Johnson AC, O'Mahony SM, Dinan TG, Greenwood-Van Meerveld B, and Cryan JF. Stress and the Microbiota-Gut-Brain Axis in Visceral Pain: Relevance to Irritable Bowel Syndrome. CNS Neurosci Ther. 2016;22(2):102-17. 
217. Verdú EF, Bercik $P$, Verma-Gandhu $M$, Huang $X X$, Blennerhassett P, Jackson W, et al. Specific probiotic therapy attenuates antibiotic induced visceral hypersensitivity in mice. Gut. 2006;55(2):182-90.

218. Eutamene H, Lamine F, Chabo C, Theodorou V, Rochat F, Bergonzelli GE, et al. Synergy between Lactobacillus paracasei and its bacterial products to counteract stress-induced gut permeability and sensitivity increase in rats. $\mathrm{J}$ Nutr. 2007;137(8):1901-7.

219. Agostini S,Goubern M,Tondereau V, Salvador-Cartier C, Bezirard V, Leveque $\mathrm{M}$, et al.A marketed fermented dairy product containing Bifidobacterium lactis CNCM I-2494 sup-presses gut hypersensitivity and colonic barrier disruption induced by acute stress in rats. Neurogastroenterol Motil. 2012;24(4):376-e172.

220. Distrutti E, Monaldi L, Ricci P, and Fiorucci S. Gut microbiota role in irritable bowel syndrome: New therapeutic strategies. World J Gastroenterol. 2016;22(7):2219-41.

221. Martin R, Makino H, Cetinyurek Yavuz A, Ben-Amor K, Roelofs M, Ishikawa E, et al. Early-Life Events, Including Mode of Delivery and Type of Feeding, Siblings and Gender, Shape the Developing Gut Microbiota. PLoS One. 2016;11(6):e0158498.

222. Weizman Z, Abu-Abed J, and Binsztok M. Lactobacillus reuteri DSM 17938 for the Management of Functional Abdominal Pain in Childhood: A Randomized, Double-Blind, PlaceboControlled Trial. J Pediatr. 2016;174:160-4.e1.

223. Spiller R, Pélerin F, Cayzeele Decherf A, Maudet C, Housez B, Cazaubiel M, et al. Randomized double blind placebocontrolled trial of Saccharomyces cerevisiae CNCM I-3856 in irritable bowel syndrome: improvement in abdominal pain and bloating in those with predominant constipation. United European Gastroenterol J. 2016;4(3):353-62.

224. Giannetti E, Maglione M, Alessandrella A, Strisciuglio C, De Giovanni D, Campanozzi A, et al. A Mixture of 3 Bifidobacteria Decreases Abdominal Pain and Improves the Quality of Life in Children With Irritable Bowel Syndrome: A Multicenter, Randomized, Double-Blind, Placebo-Controlled, Crossover Trial. J Clin Gastroenterol. 2017;51(1):e5-e10.

225. MacPherson CW, Shastri P, Mathieu O, Tompkins TA, and Burguiere P. Genome-Wide Immune Modulation of TLR3Mediated Inflammation in Intestinal Epithelial Cells Differs between Single and Multi-Strain Probiotic Combination. PLoS One. 2017;12(1):e0169847.

226. Choi HH, and Cho YS. Fecal Microbiota Transplantation: Current Applications, Effectiveness, and Future Perspectives. Clin Endosc. 2016;49(3):257-65.

227. Cammarota G, Ianiro G, Tilg H, Rajilic-Stojanovic M, Kump P, Satokari R, et al. European consensus conference on faecal microbiota transplantation in clinical practice. Gut. 2017;66(4):569-80.

228. Xu D, Chen VL, Steiner CA, Berinstein JA, Eswaran S, Waljee AK, et al. Efficacy of Fecal Microbiota Transplantation in Irritable Bowel Syndrome: A Systematic Review and MetaAnalysis. Am J Gastroenterol. 2019;114(7):1043-50.

229. Cash BD, Pimentel M, Rao SSC, Weinstock L, Chang L, Heimanson Z, et al. Repeat treatment with rifaximin improves irritable bowel syndrome-related quality of life: a secondary analysis of a randomized, double-blind, placebo-controlled trial. Therap Adv Gastroenterol. 2017;10(9):689-99.

230. Chang L, Pimentel M, Lembo A, Barrett AC, Yu J, Bortey E,et al.Mo1261 characterizing the effect of rifaximin on individual symptoms of IBS-D:findings from the open label phase of TAR-
GET 3. Gastroenterology. 2015;148(4):S-653.

231. Pimentel M, Lembo A, Chey WD, Zakko S, Ringel Y, Yu J, et al. Rifaximin therapy for patients with irritable bowel syndrome without constipation. N Engl J Med. 2011;364(1):22-32.

232. Acosta A, Camilleri M, Shin A, Linker Nord S, O'Neill J, Gray AV, et al. Effects of Rifaximin on Transit, Permeability, Fecal Microbiome, and Organic Acid Excretion in Irritable Bowel Syndrome. Clin Transl Gastroenterol. 2016;7:e173.

233. Manabe N, Rao AS, Wong BS, and Camilleri M. Emerging pharmacologic therapies for irritable bowel syndrome. Curr Gastroenterol Rep. 2010;12(5):408-16.

234. Tack J, Fried M, Houghton LA, Spicak J, and Fisher G. Systematic review: the efficacy of treatments for irritable bowel syndrome - a European perspective. Alimentary Pharmacology \& Therapeutics. 2006;24(2):183-205.

235. Quartero AO, Meiniche-Schmidt V, Muris J, Rubin G, and de Wit N. Bulking agents, antispasmodic and antidepressant medication for the treatment of irritable bowel syndrome. Cochrane Database of Systematic Reviews. 2005(2).

236. Clavé P, Acalovschi M, Triantafillidis JK, Uspensky YP, Kalayci C, Shee V, et al. Randomised clinical trial: otilonium bromide improves frequency of abdominal pain, severity of distention and time to relapse in patients with irritable bowel syndrome. Alimentary Pharmacology \& Therapeutics. 2011;34(4):432-42.

237. Ford AC, Talley NJ, Spiegel BM, Foxx-Orenstein AE, Schiller L, Quigley EM, et al. Effect of fibre, antispasmodics, and peppermint oil in the treatment of irritable bowel syndrome: systematic review and meta-analysis. Bmj. 2008;337:a2313.

238. Khanna R, MacDonald JK, and Levesque BG. Peppermint oil for the treatment of irritable bowel syndrome: a systematic review and meta-analysis. Journal of clinical gastroenterology. 2014;48(6):505-12.

239. Cash BD, Epstein MS, and Shah SM. A novel delivery system of peppermint oil is an effective therapy for irritable bowel syndrome symptoms. Digestive diseases and sciences. 2016;61(2):560-71.

240. Walstab J, Wohlfarth C, Hovius R, Schmitteckert S, Röth R, Lasitschka F, et al. Natural compounds boldine and menthol are antagonists of human 5-HT 3 receptors: implications for treating gastrointestinal disorders. Neurogastroenterology \& Motility. 2014;26(6):810-20.

241. Galeotti N, Mannelli LDC, Mazzanti G, Bartolini A, and Ghelardini C. Menthol: a natural analgesic compound. Neuroscience letters. 2002;322(3):145-8.

242. Liu B, Fan L, Balakrishna S, Sui A, Morris JB, and Jordt S-E. TRPM8 is the principal mediator of menthol-induced analgesia of acute and inflammatory pain. PAIN®. 2013;154(10):216977.

243. Harrington AM, Hughes PA, Martin CM, Yang J, Castro J, Isaacs $\mathrm{NJ}$, et al. A novel role for TRPM8 in visceral afferent function. Pain. 2011;152(7):1459-68.

244. Botschuijver S, Welting O, Levin E, Maria-Ferreira D, Koch E, Montijn R, et al. Reversal of visceral hypersensitivity in rat by Menthacarin ${ }^{\circledR}$, a proprietary combination of essential oils from peppermint and caraway, coincides with mycobiome modulation. Neurogastroenterology \& Motility. 2018;30(6):e13299.

245. Kendig DM, and Grider JR. Serotonin and colonic motility. Neurogastroenterol Motil. 2015;27(7):899-905.

246. radesi S, Lao L, McLean PG, Winchester WJ, Lee K, Hicks GA, et al. Dual role of 5-HT3 receptors in a rat model of delayed stress-induced visceral hyperalgesia. Pain.2007;130(1-2):56-65. 
247. Ford AC, Brandt LJ, Young C, Chey WD, Foxx-Orenstein AE, and Moayyedi P. Efficacy of 5-HT3 antagonists and 5-HT4 agonists in irritable bowel syndrome: systematic review and meta-analysis. Am J Gastroenterol. 2009;104(7):1831-43; quiz 44.

248. Fayyaz M, and Lackner JM. Serotonin receptor modulators in the treatment of irritable bowel syndrome. Ther Clin Risk Manag. 2008;4(1):41-8.

249. Bielefeldt K. Ischemic Colitis as a Complication of Medication Use: An Analysis of the Federal Adverse Event Reporting System. Dig Dis Sci. 2016;61(9):2655-65.

250. Crowell MD. Role of serotonin in the pathophysiology of the irritable bowel syndrome.Br J Pharmacol 2004;141(8):1285-93.

251. Tornblom H, and Drossman DA. Psychotropics, Antidepressants, and Visceral Analgesics in Functional Gastrointestinal Disorders. Curr Gastroenterol Rep. 2018;20(12):58.

252. Mikocka-Walus A, Turnbull D, Moulding N, Wilson I, Andrews JM, and Holtmann G. Psychological comorbidity and complexity of gastrointestinal symptoms in clinically diagnosed irritable bowel syndrome patients. J Gastroenterol Hepatol. 2008;23(7 Pt 1):1137-43.

253. Lee CW, Lin CL, Sung FC, Liang JA, and $\mathrm{Kao} \mathrm{CH}$. Antidepressant treatment and risk of dementia: a populationbased, retrospective case-control study. J Clin Psychiatry. 2016;77(1):117-22; quiz 22

254. Johanson JF, Drossman DA, Panas R, Wahle A, and Ueno R. Clinical trial: phase 2 study of lubiprostone for irritable bowel syndrome with constipation. Aliment Pharmacol Ther. 2008;27(8):685-96.

255. Waldman SA, and Camilleri M. Guanylate cyclase-C as a therapeutic target in gastrointestinal disorders. Gut. 2018;67(8):1543-52.

256. Johnston JM, Kurtz CB, MacDougall JE, Lavins BJ, Currie MG, Fitch DA, et al. Linaclotide improves abdominal pain and bowel habits in a phase IIb study of patients with irritable bowel syndrome with constipation. Gastroenterology. 2010;139(6):1877-86. e2.

257. Rao SS, Quigley EM, Shiff SJ, Lavins BJ, Kurtz CB, MacDougall JE, et al. Effect of linaclotide on severe abdominal symptoms in patients with irritable bowel syndrome with constipation. Clinical Gastroenterology and Hepatology. 2014;12(4):616-23

258. Castro J, Harrington AM, Hughes PA, Martin CM, Ge P, Shea $\mathrm{CM}$, et al. Linaclotide inhibits colonic nociceptors and relieves abdominal pain via guanylate cyclase-C and extracellular cyclic guanosine 3', 5'-monophosphate. Gastroenterology. 2013;145(6):1334-46. e11.

259. Rao S, Lembo AJ, Shiff SJ, Lavins BJ, Currie MG, Jia XD, et al. A 12-week, randomized, controlled trial with a 4-week randomized withdrawal period to evaluate the efficacy and safety of linaclotide in irritable bowel syndrome with constipation. The American journal of gastroenterology. 2012;107(11): 1714 .

260. Chey WD, Lembo AJ, Lavins BJ, Shiff SJ, Kurtz CB, Currie $\mathrm{MG}$, et al. Linaclotide for irritable bowel syndrome with constipation: a 26-week, randomized, double-blind, placebocontrolled trial to evaluate efficacy and safety. American Journal of Gastroenterology. 2012;107(11):1702-12.

261. Miner Jr PB, Koltun WD, Wiener GJ, De La Portilla M, Prieto B, Shailubhai K, et al. A randomized phase III clinical trial of plecanatide, a uroguanylin analog, in patients with chronic idiopathic constipation. The American journal of gatroenterolo- gy. 2017;112(4):613

262. Hellström PM, Saito YA, Bytzer P, Tack J, Mueller-Lissner S, and Chang L. Characteristics of acute pain attacks in patients with irritable bowel syndrome meeting Rome III criteria. American Journal of Gastroenterology. 2011;106(7):1299-307.

263. Wade P, Palmer J, McKenney S, Kenigs V, Chevalier K, Moore $\mathrm{B}$, et al. Modulation of gastrointestinal function by MuDelta, a mixed $\mu$ opioid receptor agonist $/ \mu$ opioid receptor antagonist. British journal of pharmacology. 2012;167(5):1111-25.

264. Lacy B. Emerging treatments in neurogastroenterology: eluxadoline-a new therapeutic option for diarrhea-predominant IBS. Neurogastroenterology \& Motility. 2016;28(1):26-35.

265. Dove LS, Lembo A, Randall CW, Fogel R, Andrae D,Davenport $\mathrm{JM}$, et al. Eluxadoline benefits patients with irritable bowel syndrome with diarrhea in a phase 2 study. Gastroenterology. 2013;145(2):329-38. e1.

266. Camilleri M. $\alpha 2 \delta$ ligand: a new, smart pill for visceral pain in patients with hypersensitive irritable bowel syndrome? Gut. 2007;56(10):1337-8.

267. Field MJ, Cox PJ, Stott E, Melrose H, Offord J, Su T-Z, et al. Identification of the $\alpha 2-\delta-1$ subunit of voltage-dependent calcium channels as a molecular target for pain mediating the analgesic actions of pregabalin. Proceedings of the National Academy of Sciences. 2006;103(46):17537-42.

268. Davis MP. Drug management of visceral pain: concepts from basic research. Pain Research and treatment. 2012;2012.

269. Million M, Wang L, Adelson D, Roman F, Diop L, and Taché Y. Pregabalin decreases visceral pain and prevents spinal neuronal activation in rats. Gut. 2007;56(10):1482-4.

270. Diop L, Raymond F, Fargeau H, Petoux F, Chovet M, and Doherty AM. Pregabalin (CI-1008) inhibits the trinitrobenzene sulfonic acid-induced chronic colonic allodynia in the rat. Journal of Pharmacology and Experimental Therapeutics. 2002;302(3):1013-22.

271. Houghton LA, Fell C, Whorwell PJ, Jones I, Sudworth D, and Gale J. Effect of a second-generation $\alpha 2 \delta$ ligand (pregabalin) on visceral sensation in hypersensitive patients with irritable bowel syndrome. Gut. 2007;56(9):1218-25.

272. Iturrino J, Camilleri M, Busciglio I, Burton D, and Zinsmeister AR. Pilot trial: pregabalin on colonic sensorimotor functions in irritable bowel syndrome. Digestive and Liver Disease. 2014;46(2):113-8.

273. Wouters MM, Balemans D, Van Wanrooy S, Dooley J, CibertGoton V, Alpizar YA, et al. Histamine receptor H1-mediated sensitization of TRPV1 mediates visceral hypersensitivity and symptoms in patients with irritable bowel syndrome. Gastroenterology. 2016;150(4):875-87. e9.

274. Wouters MM, Van Wanrooy S, Nguyen A, Dooley J, AguileraLizarraga J, Van Brabant W, et al. Psychological comorbidity increases the risk for postinfectious IBS partly by enhanced susceptibility to develop infectious gastroenteritis. Gut. 2016;65(8):1279-88.

275. Deiteren A, De Man JG, Ruyssers NE, Moreels TG, Pelckmans $\mathrm{PA}$, and De Winter BY. Histamine $\mathrm{H} 4$ and $\mathrm{H} 1$ receptors contribute to postinflammatory visceral hypersensitivity. Gut. 2014;63(12):1873-82.

276. Klooker TK, Braak B, Koopman KE, Welting O, Wouters MM, van der Heide $\mathrm{S}$, et al. The mast cell stabiliser ketotifen decreases visceral hypersensitivity and improves intestinal symptoms in patients with irritable bowel syndrome. Gut. 2010;59(9):1213-21.

277. Wouters MM, Balemans D, Van Wanrooy S, Dooley J, CibertGoton V, Alpizar YA, et al. Histamine Receptor H1- Mediated 
Sensitization of TRPV1 Mediates Visceral Hypersensitivity and Symptoms in Patients With Irritable Bowel Syndrome. Gastroenterology. 2016;150(4):875-87.e9.

278. Latremoliere A, and Woolf CJ. Central sensitization: a generator of pain hypersensitivity by central neural plasticity. The Journal of Pain. 2009;10(9):895-926.

279. Wesselmann U, Baranowski AP, Börjesson M, Curran NC, Czakanski PP, Giamberardino MA, et al. Emerging therapies and novel approaches to visceral pain. Drug Discovery Today: Therapeutic Strategies. 2009;6(3):89-95.

280. Corsetti M, Akyuz F, Tack J. Targeting tachykinin receptors for the treatment of functional gastrointestinal disorders with a focus on irritable bowel syndrome. Neurogastroenterol \& Motil 2015;27(10):1354-70.

281. Tack J, Schumacher K, Tonini G, Scartoni S, Capriati A, and Maggi C. The neurokinin-2 receptor antagonist ibodutant improves overall symptoms, abdominal pain and stool pattern in female patients in a phase II study of diarrhoea-predominant IBS. Gut. 2017;66(8):1403-13.

282. Page AJ, Brierley SM, Martin CM, Price MP, Symonds E, Butler R, et al. Different contributions of ASIC channels 1a, 2, and 3 in gastrointestinal mechanosensory function. Gut. 2005;54(10):1408-15.

283. Blackburn-Munro G, Dalby-Brown W, Mirza N, Mikkelsen J, and Blackburn-Munro R. Retigabine: chemical synthesis to clinical application. CNS drug reviews. 2005;11(1):1-20.

284. Hirano K, Kuratani K, Fujiyoshi M, Tashiro N, Hayashi E, and Kinoshita M. Kv7. 2-7.5 voltage-gated potassium channel (KCNQ2-5) opener, retigabine, reduces capsaicin-induced visceral pain in mice. Neuroscience letters. 2007;413(2):159-62.

285. Mannelli LDC, Lucarini E, Micheli L, Mosca I, Ambrosino P, Soldovieri MV, et al. Effects of natural and synthetic isothiocyanate-based H2S-releasers against chemotherapyinduced neuropathic pain: Role of Kv7 potassium channels. Neuropharmacology. 2017;121:49-59.

286. Boucher TJ, Okuse K, Bennett DL, Munson JB, Wood JN, and McMahon SB. Potent analgesic effects of GDNF in neuropathic pain states. Science. 2000;290(5489):124-7.

287. Malykhina AP, Lei Q, Erickson CS, Epstein ML, Saban MR, Davis CA, et al. VEGF induces sensory and motor peripheral plasticity, alters bladder function, and promotes visceral sensitivity. BMC Physiol. 2012;12:15.

288. Cenac N, Andrews CN, Holzhausen M, Chapman K, Cottrell G, Andrade-Gordon $\mathrm{P}$, et al. Role for protease activity in visceral pain in irritable bowel syndrome. $\mathrm{J}$ Clin Invest. 2007;117(3):636-47.

289. Vicuna L, Strochlic DE, Latremoliere A, Bali KK, Simonetti M, Husainie D, et al. The serine protease inhibitor SerpinA3N attenuates neuropathic pain by inhibiting $\mathrm{T}$ cell-derived leukocyte elastase. Nat Med. 2015;21(5):518-23.

290. Vergnolle N. Protease inhibition as new therapeutic strategy for GI diseases. Gut. 2016;65(7):1215-24.

291. Cenac N, Altier C, Motta JP, d'Aldebert E, Galeano S, Zamponi $\mathrm{GW}$, et al. Potentiation of TRPV4 signalling by histamine and serotonin: an important mechanism for visceral hypersensitivity. Gut. 2010;59(4):481-8.

292. Kondo T, Obata K, Miyoshi K, Sakurai J, Tanaka J, Miwa H, et al. Transient receptor potential A1 mediates gastric distentioninduced visceral pain in rats. Gut. 2009;58(10):1342-52.

293. Jones RC, 3rd, Xu L, and Gebhart GF. The mechanosensitivity of mouse colon afferent fibers and their sensitization by inflammatory mediators require transient receptor potential vanilloid 1 and acid-sensing ion channel 3. J Neurosci. 2005;25(47):10981-9.
294. McKernan DP, Nolan A, Brint EK, O'Mahony SM, Hyland NP, Cryan JF, et al. Toll-like receptor mRNA expression is selectively increased in the colonic mucosa of two animal models relevant to irritable bowel syndrome. PLoS One. 2009;4(12):e8226.

295. Taché Y, Kiank C, and Stengel A. A role for corticotropinreleasing factor in functional gastrointestinal disorders. Current gastroenterology reports. 2009;11(4):270-7.

296. Antonioli L, Fornai M, Colucci R, Ghisu N, Tuccori M, Del Tacca M, et al. Regulation of enteric functions by adenosine: pathophysiological and pharmacological implications. Pharmacol Ther. 2008;120(3):233-53.

297. Burnstock G. Purinergic mechanosensory transduction and visceral pain. Mol Pain. 2009;5:69-

298. Deiteren A, van der Linden L, de Wit A, Ceuleers H, Buckinx $\mathrm{R}$, Timmermans J-P, et al. P2X3 receptors mediate visceral hypersensitivity during acute chemically-induced colitis and in the post-inflammatory phase via different mechanisms of sensitization. PloS one. 2015;10(4):e0123810-e.

299. Silverman MH, Strand V, Markovits D, Nahir M, Reitblat T, Molad Y, et al. Clinical evidence for utilization of the A3 adenosine receptor as a target to treat rheumatoid arthritis: data from a phase II clinical trial. The Journal of Rheumatology. 2008;35(1):41

300. Di Cesare Mannelli L, Marcoli M, Micheli L, Zanardelli M, Maura G, Ghelardini C, et al. Oxaliplatin evokes P2X7dependent glutamate release in the cerebral cortex: A pain mechanism mediated by Pannexin 1. Neuropharmacology. 2015;97:133-41.

301. Zylka MJ. Pain-relieving prospects for adenosine receptors and ectonucleotidases. Trends Mol Med. 2011;17(4):188-96.

302. Little JW, Ford A, Symons-Liguori AM, Chen Z, Janes K, Doyle T, et al. Endogenous adenosine A3 receptor activation selectively alleviates persistent pain states. Brain. 2015;138(Pt 1):28-35.

303. Chen Z, Janes K, Chen C, Doyle T, Bryant L, Tosh DK, et al. Controlling murine and rat chronic pain through A3 adenosine receptor activation. Faseb j. 2012;26(5):1855-65.

304. Tosh DK, Padia J, Salvemini D, and Jacobson KA. Efficient, large-scale synthesis and preclinical studies of MRS5698, a highly selective A3 adenosine receptor agonist that protects against chronic neuropathic pain. Purinergic Signal. 2015;11(3):371-87.

305. Luongo L, Petrelli R, Gatta L, Giordano C, Guida F, Vita P, et al. 5'-Chloro-5'-deoxy-(+/-)-ENBA, a potent and selective adenosine $\mathrm{A}(1)$ receptor agonist, alleviates neuropathic pain in mice through functional glial and microglial changes without affecting motor or cardiovascular functions. Molecules. 2012;17(12):13712-26.

306. Ren T, Tian T, Feng X, Ye S, Wang H, Wu W, et al. An adenosine A3 receptor agonist inhibits DSS-induced colitis in mice through modulation of the NF-kappaB signaling pathway. Sci Rep. 2015;5:9047.

307. Varani K, Vincenzi F, Targa M, Paradiso B, Parrilli A, Fini M, et al. The stimulation of $\mathrm{A}(3)$ adenosine receptors reduces boneresiding breast cancer in a rat preclinical model. Eur J Cancer. 2013;49(2):482-91.

308. Yan H, Zhang E, Feng C, and Zhao X. Role of A3 adenosine receptor in diabetic neuropathy. J Neurosci Res. 2016;94(10):936-46.

309. Bolyen E, Rideout JR, Dillon MR, Bokulich NA, Abnet CC, AlGhalith GA, et al. Reproducible, interactive, scalable and extensible microbiome data science using QIIME 2. Nat Biotechnol. 2019;37(8):852-7. 
310. Coppi E, Cherchi F, Fusco I, Failli P, Vona A, Dettori I, et al Adenosine A3 receptor activation inhibits pronociceptive $\mathrm{N}$ type $\mathrm{Ca} 2+$ currents and cell excitability in dorsal root ganglion neurons. Pain. 2019;160(5):1103-18.

311. Christianson JA, and Gebhart GF. Assessment of colon sensitivity by luminal distension in mice. Nat Protoc. 2007;2(10):2624-31.

312. O'Mahony SM, Tramullas M, Fitzgerald P, and Cryan JF. Rodent Models of Colorectal Distension. Current Protocols in Neuroscience. 2012;61(1):9.40.1-9..13.

313. Chen Y, Lin C, Tang Y, Chen A-Q, Liu C-Y, and Lu D-L. ZD 7288 , an HCN channel blocker, attenuates chronic visceral pain in irritable bowel syndrome-like rats. World J Gastroenterol 2014;20(8):2091-7.

314. Greenwood-Van Meerveld B, Prusator DK, and Johnson AC. Animal models of gastrointestinal and liver diseases. Animal models of visceral pain: pathophysiology, translational relevance, and challenges. Am J Physiol Gastrointest Liver Physiol. 2015;308(11):G885-903.

315. Trimble N, Johnson AC, Foster A, and Greenwood-van Meerveld B. Corticotropin-releasing factor receptor 1-deficient mice show decreased anxiety and colonic sensitivity. Neurogastroenterol Motil. 2007;19(9):754-60.

316. Gunter WD, Shepard JD, Foreman RD, Myers DA, and Greenwood-Van Meerveld B. Evidence for visceral hypersensitivity in high-anxiety rats. Physiol Behav. 2000;69(3):379-82.

317. o'malley D, Julio-Pieper M, Gibney SM, Gosselin RD, Dinan TG, and Cryan JF. Differential stress-induced alterations of colonic corticotropin-releasing factor receptors in the Wistar Kyoto rat. Neurogastroenterol Motil. 2010;22(3):301-11.

318. Buckley MM, O'Halloran KD, Rae MG, Dinan TG, and O'Malley D. Modulation of enteric neurons by interleukin-6 and corticotropin-releasing factor contributes to visceral hypersensitivity and altered colonic motility in a rat model of irritable bowel syndrome. J Physiol. 2014;592(23):5235-50.

319. Taylor SE. Mechanisms linking early life stress to adult health outcomes. Proc Natl Acad Sci U S A. 2010;107(19):8507-12.

320. Plotsky PM, and Meaney MJ. Early, postnatal experience alters hypothalamic corticotropin-releasing factor (CRF) mRNA median eminence CRF content and stress-induced release in adult rats. Brain Res Mol Brain Res. 1993;18(3):195-200.

321. Coutinho SV, Plotsky PM, Sablad M, Miller JC, Zhou H, Bayati AI, et al. Neonatal maternal separation alters stress-induced responses to viscerosomatic nociceptive stimuli in rat. Am $\mathbf{J}$ Physiol Gastrointest Liver Physiol. 2002;282(2):G307-16.

322. Dinan TG, Quigley EM, Ahmed SM, Scully P, O'Brien S, O'Mahony L, et al. Hypothalamic-pituitary-gut axis dysregulation in irritable bowel syndrome: plasma cytokines as a potential biomarker? Gastroenterology. 2006;130(2):304-11.

323. Sullivan RM, Landers M, Yeaman B, and Wilson DA. Good memories of bad events in infancy. Nature. 2000;407(6800):389 .

324. Wilson DA, and Sullivan RM. Neurobiology of associative learning in the neonate: Early olfactory learning. Behavioral and Neural Biology. 1994;61(1):1-18.

325. Chaloner A, and Greenwood-Van Meerveld B. Sexually dimorphic effects of unpredictable early life adversity on visceral pain behavior in a rodent model. $J$ Pain. 2013;14(3):270-80

326. Bradford K, Shih W, Videlock EJ, Presson AP, Naliboff BD, Mayer EA, et al. Association between early adverse life events and irritable bowel syndrome. Clin Gastroenterol Hepatol. 2012;10(4):385-90.e1-3.
327. Gilles EE, Schultz L, and Baram TZ. Abnormal corticosterone regulation in an immature rat model of continuous chronic stress. Pediatr Neurol. 1996;15(2):114-9.

328. Prusator DK, Andrews A, and Greenwood-Van Meerveld B. Neurobiology of early life stress and visceral pain: translational relevance from animal models to patient care. Neurogastroenterol Motil. 2016;28(9):1290-305.

329. Al-Chaer ED, Kawasaki M, and Pasricha PJ. A new model of chronic visceral hypersensitivity in adult rats induced by colon irritation during postnatal development. Gastroenterology. 2000;119(5):1276-85.

330. Chaloner A, Rao A, Al-Chaer ED, and Greenwood-Van Meerveld B. Importance of neural mechanisms in colonic mucosal and muscular dysfunction in adult rats following neonatal colonic irritation. Int J Dev Neurosci. 2010;28(1):99103.

331. Lin C, and Al-Chaer ED. Long-term sensitization of primary afferents in adult rats exposed to neonatal colon pain. Brain Res. 2003;971(1):73-82.

332. Greenwood-Van Meerveld B, Gibson M, Gunter W, Shepard J, Foreman R, and Myers D. Stereotaxic delivery of corticosterone to the amygdala modulates colonic sensitivity in rats. Brain Res. 2001;893(1-2):135-42.

333. Naliboff BD, Berman S, Chang L, Derbyshire SW, Suyenobu B, Vogt BA, et al. Sex-related differences in IBS patients: central processing of visceral stimuli. Gastroenterology. 2003;124(7):1738-47.

334. Wilder-Smith CH, Schindler D, Lovblad K, Redmond SM, and Nirkko A. Brain functional magnetic resonance imaging of rectal pain and activation of endogenous inhibitory mechanisms in irritable bowel syndrome patient subgroups and healthy controls. Gut. 2004;53(11):1595-601.

335. Myers B, and Greenwood-Van Meerveld B. Corticosteroid receptor-mediated mechanisms in the amygdala regulate anxiety and colonic sensitivity. Am J Physiol Gastrointest Liver Physiol. 2007;292(6):G1622-9.

336. Taguchi R, Shikata K, Furuya Y, Hirakawa T, Ino M, Shin K, et al. Selective corticotropin-releasing factor 1 receptor antagonist E2508 reduces restraint stress-induced defecation and visceral pain in rat models. Psychoneuroendocrinology. 2017;75:110-5.

337. Larauche M, Mulak A, Kim YS, Labus J, Million M, and Taché Y. Visceral analgesia induced by acute and repeated water avoidance stress in rats: sex difference in opioid involvement. Neurogastroenterology and motility : the official journal of the European Gastrointestinal Motility Society. 2012;24(11):1031e547.

338. Larauche M, Mulak A, Yuan PQ, Kanauchi O, and Tache Y. Stress-induced visceral analgesia assessed non-invasively in rats is enhanced by prebiotic diet. World J Gastroenterol. 2012;18(3):225-36.

339. Langlois A, Diop L, Rivière PJM, Pascaud X, and Junien J-L. Effect of fedotozine on the cardiovascular pain reflex induced by distension of the irritated colon in the anesthetized rat. European Journal of Pharmacology. 1994;271(2):245-51.

340. Plourde V, St-Pierre S, and Quirion R. Calcitonin gene-related peptide in viscerosensitive response to colorectal distension in rats. Am J Physiol. 1997;273(1 Pt 1):G191-6.

341. Bourdu S, Dapoigny M, Chapuy E, Artigue F, Vasson M-P, Dechelotte P, et al. Rectal instillation of butyrate provides a novel clinically relevant model of noninflammatory colonic hypersensitivity in rats. Gastroenterology. 2005;128(7):19962008.

342. Qin HY, Xiao HT, Wu JC, Berman BM, Sung JJ, and Bian ZX. Key factors in developing the trinitrobenzene sulfonic acid- 
induced post-inflammatory irritable bowel syndrome model in rats. World J Gastroenterol. 2012;18(20):2481-92.

343. Hu X, Zhang X, Han B, and Bei W. The inhibitory effect of tongxieyaofang on rats with post infectious irritable bowel syndrome through regulating colonic par-2 receptor. BMC Complement Altern Med. 2013;13:246-.

344. Ibeakanma C, Miranda-Morales M, Richards M, Bautista-Cruz F, Martin N, Hurlbut D, et al. Citrobacter rodentium colitis evokes post-infectious hyperexcitability of mouse nociceptive colonic dorsal root ganglion neurons. J Physiol. 2009;587(Pt 14):3505-21.

345. Ibeakanma C, Ochoa-Cortes F, Miranda-Morales M, McDonald T, Spreadbury I, Cenac N, et al. Brain-gut interactions increase peripheral nociceptive signaling in mice with postinfectious irritable bowel syndrome. Gastroenterology. 2011;141(6):2098108.e5.

346. Yang X, Sheng L, Guan Y, Qian W, and Hou X. Synaptic plasticity: the new explanation of visceral hypersensitivity in rats with Trichinella spiralis infection? Dig Dis Sci. 2009;54(5):937-46.

347. Hughes PA, Brierley SM, Martin CM, Brookes SJ, Linden DR, and Blackshaw LA. Post-inflammatory colonic afferent sensitisation: different subtypes, different pathways and different time courses. Gut. 2009;58(10):1333-41.

348. Chen Y, Xiao S, Gong Z, Zhu X, Yang Q, Li Y, et al. Wuji Wan Formula Ameliorates Diarrhea and Disordered Colonic Motility in Post-inflammation Irritable Bowel Syndrome Rats by Modulating the Gut Microbiota. Front Microbiol. 2017;8:2307.

349. Chassaing B, Aitken JD, Malleshappa M, and Vijay-Kumar M. Dextran sulfate sodium (DSS)-induced colitis in mice. Curr Protoc Immunol. 2014;104:15.25.1-15.25.14.
350. Eichele DD, and Kharbanda KK. Dextran sodium sulfate colitis murine model: An indispensable tool for advancing our understanding of inflammatory bowel diseases pathogenesis. World J Gastroenterol. 2017;23(33):6016-29.

351. Chen J, Winston JH, and Sarna SKNeurological and cellular regulation of visceral hypersensitivity induced by chronic stress and colonic inflammation in rats. Neuroscience. 2013;248:46978.

352. Eijkelkamp N, Heijnen CJ, Elsenbruch S, Holtmann G, Schedlowski M,Kavelaars A. G protein-coupled receptor kinase 6 controls post-inflammatory visceral hyperalgesia. Brain, behavior, and immunity. 2009;23(1):18-26.

353. Qin HY, Wu JC, Tong XD, Sung JJ, Xu HX, Bian ZX. Systematic review of animal models of post-infectious/postinflammatory irritable bowel syndrome. J Gastroenterol 2011;46(2):164-74.

354. te Velde AA, Verstege MI, Hommes DW. Critical appraisal of the current practice in murine TNBS-induced colitis. Inflamm Bowel Dis. 2006;12(10):995-9.

355. Greenwood-Van Meerveld B, Venkova K, Hicks G, Dennis E, Crowell MD. Activation of peripheral 5-HT receptors attenuates colonic sensitivity to intraluminal distension.Neurogatroenterol Motil. 2006;18(1):76-86.

356. Fornai M, Blandizzi C, Antonioli L, Colucci R, Bernardini N, Segnani C, et al. Differential role of cyclooxygenase 1 and 2 isoforms in the modulation of colonic neuromuscular function in experimental inflammation.J Pharmacol Exp Ther.2006; 317(3):938-45.

357. Zhou Q, Price DD, Caudle RM, and Verne GN. Spinal NMDA NR1 subunit expression following transient TNBS colitis. Brain research. 2009;1279:109-20. 